\title{
RESEARCH
}

\section{Restructuring and the scope of negation in Hindi-Urdu}

\author{
Vincent Homer ${ }^{1}$ and Rajesh Bhatt ${ }^{2}$ \\ ${ }^{1}$ CNRS, Jean Nicod - UMass Amherst, ILC, Amherst, MA, US \\ 2 UMass Amherst, ILC, Amherst, MA, US \\ Corresponding author: (vincenthomer@umass.edu)
}

In Hindi-Urdu, a negation which seems to be inside an infinitival complement can have effects typical of a matrix negation, e.g., NPI licensing in the matrix. We show that this exceptional behavior of negation is only possible with restructuring infinitives. We argue that the infinitival V moves out of the restructuring infinitive and into the matrix, and that it forms a cluster with the main verb. This movement makes the negative marker appear to belong to the embedded clause, when in fact it is in the matrix, and behaves as a matrix negation (in terms of scope and other tests). We thus have a new criterion for restructuring in Hindi-Urdu, alongside Long Distance Agreement. The existence of these two criteria allows us to explore the diversity of restructuring complements in Hindi-Urdu and show that the optionality of Long Distance Agreement is not tied to the optionality of restructuring.

Keywords: Restructuring; negation; Hindi-Urdu; neg-raising; agreement; head movement; clustering

\section{Introduction}

For a class of infinitival clauses in Hindi-Urdu, we find a puzzling state of affairs with negation: a negation which seems to be inside an infinitival complement has effects typical of a matrix negation, e.g., NPI licensing in the matrix. This puzzle was already observed by Mahajan (1990), Bhatt (2005) and Kumar (2006):
Seemingly embedded negation licenses a matrix NPI: ${ }^{1}$
ek-bhii laṛke-ne Mina-kii madad nahĩ: kar-nii caah-ii
one-even boy-ERG Mina-GEN.F help.F NEG do-INF.F want-PFV.F
'Not even a single boy wanted to help Mina.'

The marker nahi: in (1) immediately precedes the embedded verb, and thus occupies the position where embedded negation is expected to surface. And yet, paradoxically, a subject NPI is licensed in the matrix: we call this the 'exceptional behavior' of negation.

In this article, we show that negation in (1) and similar examples is in the matrix, despite appearances to the contrary. We argue that it only looks embedded because the infinitival verb undergoes movement to the matrix and forms a cluster with the main verb. This movement is possible out of restructuring infinitives, e.g., the complement of want, and only them. We use the phrase 'verb cluster' in a specific sense, borrowed from

\footnotetext{
${ }^{1}$ Unless attributed to published sources, the Hindi-Urdu judgments reported in this article come from the second author. These judgments have also been confirmed with other native speaker linguists. The bulk of the data was presented in a talk at the Formal Approaches to South Asian Languages (FASAL) conference and as a lecture at the Linguistic Summer School in the Indian Mountains (LISSIM). Both venues had a significant number of Hindi-Urdu speakers in the audience.
} 
Keine \& Bhatt 2016: by it, we mean complex verbal head formation. ${ }^{2}$ Head movement makes the negative marker appear to belong to the embedded clause, when in fact it is in the matrix, and behaves as a matrix negation (in terms of scope and other tests).

Our treatment of the scope of negation in infinitival clauses reveals a landscape that is similar to the one identified in the literature on restructuring infinitives in Germanic. Our derivation of the exceptional behavior of negation implicates cluster formation, which is only possible with restructuring infinitives. But restructuring infinitives do not require cluster formation as shown by the fact that Long Distance Agreement, a restructuring diagnostic, is possible even when cluster formation doesn't happen. ${ }^{3}$ Keine \& Bhatt (2016) show that in situ German long passives involve obligatory cluster formation (see also Haider 1993; 2010; 2003) but that cluster formation is not essential to long passives, a point originally made by Wurmbrand (2001). We have identified one difference between cluster formation in Hindi-Urdu and German-Keine \& Bhatt (2016) argued that the cluster formation operation in the long passive is semantically contentful but we show that the cluster formation operation that we propose for Hindi-Urdu is semantically vacuous.

This article has the following structure. As background for the explanation of the exceptional behavior of negation, we investigate the location of sentential negation in the HindiUrdu clause, and determine that rightward V movement to the negative marker happens in simplex clauses (Sect. 2). In Sect. 3, we show that the exceptional behavior requires restructuring. We then propose that restructuring allows the infinitival verb to move into the matrix, where it forms a complex head with the main verb (Sect. 4): this cluster moves to the right of the matrix negative marker, thus deriving a surface order which falsely suggests an embedded negation; in this section we also discuss the implications of the apparent optionality of verb clustering for the theory of restructuring. Sect. 5 examines the exceptional behavior of negation under the alternative hypothesis that the negative marker in Hindi-Urdu is distinct from the actual negation, a covert morpheme; we argue against this hypothesis, which renders verb clustering unnecessary and unobservable. Finally, we compare verb clustering in Hindi-Urdu and its equivalent in German (Sect. 6).

\section{Background on negation in Hindi-Urdu}

In this section, we provide a partial description of negation in Hindi-Urdu. We make a new claim about its height: we argue that it is higher than the canonical surface position of subjects. ${ }^{4}$ We also show that the negative marker nahĩ:, if negative, sits to the right of V (in agreement with Kumar 2006).

\subsection{Surface position of the negative marker}

The presence of negation is marked by nahĩ, which appears in almost all environments. ${ }^{5}$ The marker nahĩ: appears as part of the verb sequence. The most normal position for it is the immediately pre-verbal one but post-verbal negation is also possible:

a. nahĩ: V Aux: default

Ram-ne seb nahĩ: khaa-yaa thaa

Ram-ERG apple.M NEG eat-PFV.MSG be.PST.MSG

'Ram had not eaten the apple/apples.'

\footnotetext{
${ }^{2}$ Wurmbrand's (2017) survey article talks about verb clusters in a broader sense: a verb cluster is a sequence of verbs whose respective order is flexible.

${ }^{3}$ Prior literature (e.g., Mahajan 1990: fn. 11) takes the fact that cluster formation does not take place with all instances of restructuring infinitives (i.e., want and the infinitival $\mathrm{V}$ can be separated by an adverb) as arguing against the very possibility of cluster formation. We argue that this is too hasty-cluster formation is actually obligatory when possible but it can be bled by movement giving the appearance of optionality. See Sect. 4.4.

${ }^{4}$ That is, the position occupied by non-scrambled subjects on the surface.

${ }^{5}$ Prohibitives are an exception: these require the special form mat. There is also naa, which is limited to nonrestructuring infinitives and subjunctives.
} 
b. V nahĩ: Aux: more emphatic, contrastive reading easily available Ram-ne seb khaa-yaa nahĩ thaa, (sirf su:ngh-aa Ram-ERG apple.M eat-PFV.MSG NEG be.PST.MSG only smell-PFV.MSG thaa) be.PST.MSG

'Ram hadn't eaten the apple(, he had merely smelled it.)'

c. V Aux nahĩ:: denial

Ram-ne seb khaa-yaa thaa nahĩ:

Ram-ERG apple.M eat-PFV.MSG be.PST NEG

'Ram had NOT eaten the apple/apples (I don't know why you are saying that he had....).'

In the unmarked 'nahĩ: V' order, adjacency is required between nahĩ: and V (Kumar 2006: 92 makes the same point):

Ram-ne seb tab nahĩ: khaayaa thaa Ram-ERG apple then NEG eat.PFV be.PST 'Ram hadn't eaten an apple then.'

(4) Violation of adjacency by tab 'then':

*Ram-ne seb nahĩ: tab khaayaa thaa

Ram-ERG apple NEG then eat.PFV be.PST

Intended: 'Ram hadn't eaten an apple then.'

There can be only one negation in a simplex clause. For example the following 'nahĩ: $\mathrm{V}$ nahĩ: Aux' order is out or quite odd:
*nahĩ: V nahĩ: Aux
*/\#Ram-ne seb nahĩ: khaa-yaa nahĩ: thaa
Ram-ERG apple.M NEG eat-PFV.MSG NEG be.PST.MSG
Intended: 'Ram had eaten the apple/apples.'

\subsection{Sentential negation}

There are at least two hallmarks of sentential negation in Hindi-Urdu, auxiliary deletion and subject NPI licensing. The former can be used specifically to detect a clausemate negation (while subject NPIs can be licensed by a superordinate negation, and are thus not a direct test for clausemate negation).

\subsubsection{Auxiliary deletion}

Ordinarily the progressive and habitual participles in Hindi-Urdu require auxiliaries to form complete free-standing clauses; this is in contrast to the perfective participle which can stand on its own.

(6) Progressive:

Ram seb khaa rahaa (hai/ thaa/ hogaa)

Ram apple eat PROG.MSG be.PRS be.PST be.FUT

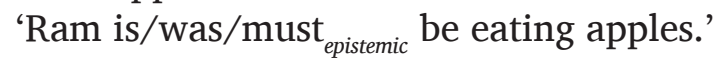

(7) Habitual:

Ram seb khaa-taa *(hai/ thaa/ hogaa)

Ram apple eat-HAB.MSG be.PRS be.PST be.FUT

'Ram eats/used to/must ${ }_{\text {epistemic }}$ eat apples.' 
However, in the presence of negation, the auxiliary can go missing. The resulting structure is interpreted as having present tense specification: ${ }^{6}$

(8) Progressive:

Ram seb nahĩ: khaa rahaa

Ram apple NEG eat PROG.MSG

'Ram is not eating apples.'

(9) Habitual:

Ram seb nahĩ: khaa-taa

Ram apple NEG eat-HAB.MSG

'Ram does not eat apples.'

We refer to this pattern as 'auxiliary deletion' (originally described by Bhatia 1978, and also discussed in Nevins \& Anand 2003, Bhatt 2005: 772 and Bhatt \& Keine 2017). In the above examples, the absence of the auxiliary has no impact on anything else-everything else stays the same. This is not always the case. For example when the subject has 3FPL features, the absence of the auxiliary changes the form of the participle. See Bhatt \& Keine 2017 for details.

\subsubsection{NPI licensing}

Sentential negation in Hindi-Urdu licenses both subject and object NPIs, and it also licenses (under some conditions) NPIs in subordinate clauses (for an in-depth study of NPIs in HindiUrdu, see Lahiri 1998):

(10) Subject NPI:

ek-bhii larke-ne seb nahĩ: khaa-yaa

one-even boy-ERG apple.M NEG eat-PFV.MSG

'Not even a single boy ate apples.'

(11) Object NPI:

Ram-ne ek-bhii seb nahĩ: khaa-yaa

Ram-ERG one-even apple.M NEG eat-PFV.MSG

'Ram did not eat even a single apple.'

\subsection{The position of sentential negation}

\subsubsection{Using scope to determine the height of sentential negation}

Where is sentential negation (abbreviated as 'NEG') in the hierarchical structure of the Hindi-Urdu clause? We will not rely on the immediately pre-verbal surface position of nahĩ:, which is not telling by itself (nahĩ: could be a specifier attached to the left of vP or a head or a specifier attached to the right of vP, see Mahajan 1990; Kumar 2006; we address the issue in the next subsection). In fact, it is in principle possible that nahĩ: is not negative, and is instead a mere correlate of a covert sentential negation (see Sect. 5). The argument that we will make now holds whether nahĩ: is negative or not. It only relies on the scope of sentential negation with respect to two other scope-taking elements in the clause, an adverb and a subject NPI. From scopal relations, we can infer relative syntactic positions.

We claim that we can work out the relative position of NEG with respect to the canonical position of subjects in Hindi-Urdu, assuming that there is only one sentential negation per clause, and that it doesn't move (we made the same argument in our Homer \& Bhatt

\footnotetext{
${ }^{6}$ A freestanding habitual participle can also be interpreted as a past habitual in certain contexts. Therefore in this paper we focus on the (un)availability of a present tense reading in the absence of an auxiliary.
} 
2019). ${ }^{7}$ Since it licenses subject NPIs (as well as object NPIs) (10), we already know that NEG is above the lowest position where a subject NPI can be interpreted, which might be a reconstructed position (we assume, in agreement with much literature, that NPIs need to be in the scope of a licenser at LF, see Homer 2019).

Now, this doesn't tell us where NEG is relative to the canonical surface position of subjects in Hindi-Urdu. As will become clear at the end of this discussion, it seems that this subject position is not Spec,TP, but rather a lower position: we will thus assume, although nothing in the ongoing discussion hinges on that decision, that it is Spec,AspP. The alternative is thus the following:

Alternative: NEG is either (i) above or (ii) below Asp in Hindi-Urdu; if (ii) is correct (and only if (ii) is correct), subject NPIs need to reconstruct under NEG at LF.

We use two overt elements: we want them to be overt, so we can track their relative surface positions. One is an NPI (the subject), which needs to be in the scope of negation at LF. The other is a fixed point, the adverb hameshaa 'always'. We say that hameshaa is a fixed point because adverbs are not believed to raise or lower covertly. To adjudicate the case, and since we are not relying on the surface position of a negative marker, but only on relative scope, we thus need to construct a configuration with three scope-taking elements.

Note first that sentential negation preferentially takes scope over hameshaa (and other adverbs), i.e., preferentially occupies a higher position:

$$
\begin{aligned}
& \text { Ram-ne hameshaa mehnat nahĩ: ki: } \\
& \text { Ram-ERG always handwork.F NEG do.PFV.F } \\
& \text { 'Ram did not work hard all the time.' }
\end{aligned}
$$

easy: $\neg \gg$ ALWAYS; marginally available: ALWAYS $\neg ~$

The adverb hameshaa thus has at least two positions; one of them is above NEG, one of them below it (we do not need to determine the absolute positions occupied by the adverb for the argument to hold, for this is an argument about relative positions). ${ }^{8}$ To create the configuration that we need in order to locate NEG w.r.t. subjects, we only have to replace the non-polarized subject with a subject NPI, ek-bhi: larke-ne 'any boy':

\section{NPI...hameshaa...nahĩ:}

ek-bhi: larke-ne hameshaa mehnat nahĩ: ki: one-even boy-ERG always handwork.F NEG do.PFV.F

'Not even one boy worked hard all the time.'

Strikingly, (14) only has a reading where NEG outscopes the adverb: this is obviously an effect of the presence of the NPI. ${ }^{9}$

\footnotetext{
7 The first assumption is supported by the ill-formedness of (5): if there cannot be more than one occurrence of the negative marker, presumably there is only one negation. There is strong crosslinguistic evidence in favor of the second assumption, see Sect. 4.5.

${ }^{8}$ Note that in English too the two scope relations exist, but they are transparently read off of surface order:

(i) a. John doesn't always vote.

b. John always doesn't vote.

${ }^{9}$ To show that the putative ALWAYS $\gg \neg \gg$ ANY (equivalent to 'no boy ever worked hard') is missing, we construct a dialogue that should be coherent if the reading is available. B's response in the following discourse is deviant, showing that (14) lacks the reading in question:
}

(i) a. A: ek-bhi: lạ̣ke-ne hameshaa mehnat nahĩ: ki: $\quad[=(14)]$ 
If NEG is above Asp, we can straightforwardly account for the availability of the $\neg \gg$ ANY \ALWAYS reading of (14): it follows from the putative position of NEG and the surface order of the other two elements. And we can also explain why the ALWAYS $\gg \neg \gg$ ANY reading is unavailable: the only way to derive it is by having hameshaa higher than NEG (remember that it can be higher or lower, per (13)), which requires scrambling the subject NPI higher than the canonical Spec,AspP position (so as to derive the surface order) and then reconstructing it at LF. Scrambled NPIs, as it turns out, cannot reconstruct. Consider (15) for example:

ek-bhi: kitaab har laṛke-ne nahĩ: paṛhi:

one-even book every boy-ERG NEG read.PFV.F

'No book is such that every boy read it.'

This sentence lacks the EVERY $\gg \neg \gg$ ANY reading, ${ }^{10}$ which indicates that the scrambled NPI cannot reconstruct (see also Homer \& Bhatt 2019).

If on the other hand NEG is below Asp, then a subject NPI needs to reconstruct ${ }^{11}$ under NEG at LF, in order to be licensed. ${ }^{12}$ This reconstruction is a relatively short one, since it doesn't bring the NPI lower than the adverb (we get a $\neg \gg$ ANY $\gg$ ALWAYS reading, with an adverb in a low position, below NEG). If reconstruction to the base position were required, the NPI would be anti-licensed, due to the intervention effect of the adverb: strong scalar terms like every, necessarily, and always are interveners in English (see Linebarger 1980

b. B: \#aap-ne bilkul sahi: kahaa ki kisi-bhi: larke-ne kabhi:-bhi: you.HON-ERG correct exactly say.PFV that some-even boy-ERG sometime-even mehnat nahĩ: ki: hardwork.F NEG do.PFV.F

'\#You said it exactly right that no boy ever worked hard.'

${ }^{10}$ To show that the reconstructed reading is missing, we use a dialogue:

(i) a. A: ek-bhi: kitaab har lậke-ne nahĩ: paṛhi: $\quad$ [= (15)]

b. B: \#aap-ne bilkul sahi: kahaa ki kisi-bhi: larke-ne koi-bhi: kitaab you.HON-ERG exactly correct say.PFV that some-even boy-ERG some-even book.F nahĩ: parhi:

NEG read.PFV.F

'\#You said it exactly right that no boy read any book.'

B's response is deviant, therefore the reading is missing. Focal stress on har larke 'every boy' makes the reading more acceptable, but we believe that this is an effect of a covert movement of the universal under focus.

${ }^{11}$ For simplicity, we only consider syntactic reconstruction (and not semantic reconstruction, see Sternefeld 2001 a.o.), as we assume that the position of an NPI at LF is what counts for its licensing.

12 That subject NPIs can reconstruct under negation is not a trivial assumption. In English and many other languages, they can't:

(i) *Anyone didn't come.

Furthermore, reconstruction of non-NPI subjects in Hindi-Urdu doesn't appear to be an option:

(ii) ek/kisi: larke-ne hameshaa mehnat ki: (hai)

a/some boy-ERG always hard.work.F do.PFV.F be.PRS.SG

'A/some boy has always worked hard.'

A/SOME $\gg A L W A Y S$

*ALWAYS $\gg \mathrm{A} / \mathrm{SOME}$

Impossible continuation: '... sometimes it was a boy from the U.S., sometimes from Canada.'

In this example, an existentially quantified subject precedes a universally quantified adverb. For inverse scope to obtain, reconstruction is the only possibility, as adverbs don't QR. The sentence lacks an inverse scope reading, unlike its English counterpart. 
and Chierchia 2004), and so are their equivalents in Hindi-Urdu. ${ }^{13}$ Consider the following surface structure tree; we mark the canonical position of subjects as 'Spec,AspP', and we arbitrarily show NEG as attached to the right of the spine (but nothing hinges on this decision: all we need is NEG under the canonical position of subjects): ${ }^{14}$

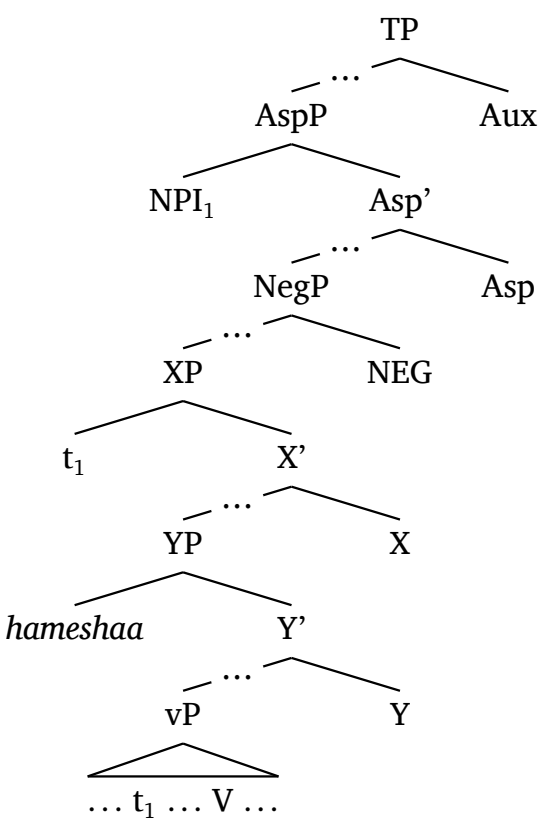

After short reconstruction of the subject NPI, we get:

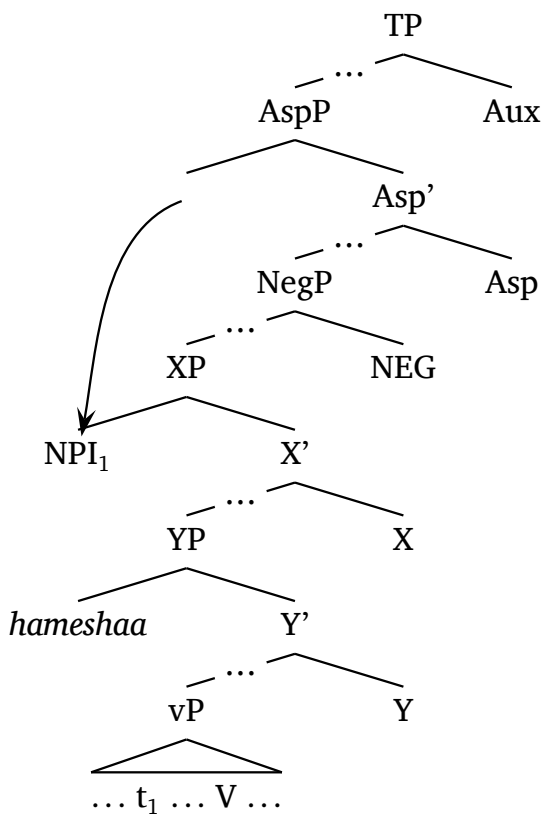

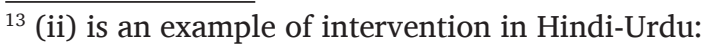

(i) har larke-ne Sita-se baat nahĩ: ki: every boy-ERG Sita-with talk NEG do.PFV.F 'Every boy didn't talk to Sita.'

(ii) har laṛke-ne ek-bhi: laṛki:-se baat nahĩ: ki:

every boy-ERG one-also girl-with talk NEG do.PFV.F

'Every boy talked to no girl.'

${ }^{14}$ Our tree representations are couched in the X-bar theory of syntax; we only show bar-levels when a specifier is projected. 
This derives the $\neg \gg$ ANY $\gg$ ALWAYS reading. The unavailability of the ALWAYS $\gg \neg \gg A N Y$ reading is surprising if NEG is below the canonical subject position: we could imagine the adverb being below Asp and above NEG (thus in a 'high' position relative to NEG), and the subject undergoing short syntactic reconstruction under NEG, as shown in (18):

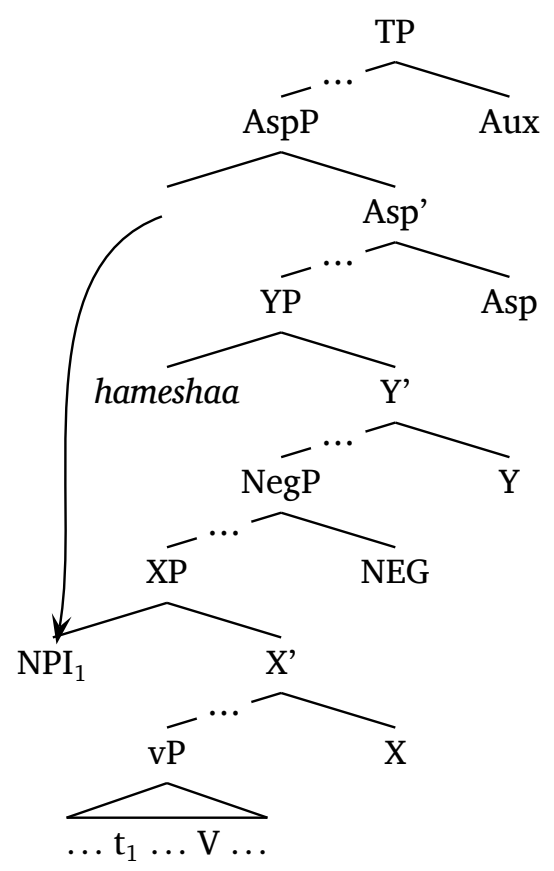

The curious consequence that short reconstruction of the subject is possible with a low hameshaa and impossible with a high hameshaa makes the hypothesis that NEG sits below the canonical subject position implausible. We could rescue it with a stipulation though: if we assume that hameshaa cannot be merged below the canonical position of subjects and above the putative position of NEG, then the only way to achieve the ALWAYS $\gg \neg \gg$ ANY reading is by having hameshaa higher than the canonical subject position on the surface. As a result, the subject NPI must first scramble past this high position on the surface (this yields the word order where the NPI precedes hameshaa (14)) and then reconstruct under NEG at LF. But we know that this is impossible (15).

The NEG-above-Asp hypothesis is superior to its contender because it derives the relevant facts with fewer assumptions. ${ }^{15}$

\subsubsection{Let's assume that NEG is nahĩ:}

In light of the preceding argument about the position of NEG, we can address the issue of the status of the negative marker nahĩ. As we said earlier, it is in principle possible that it is different from NEG. But for now, we will identify nahĩ: with NEG. We explore the alternative option (NEG is distinct from nahĩ:) in Sect. 5.

(19) Assumption: The negative marker nahĩ: is semantically negative, i.e., it is NEG.

Given that NEG is higher than the canonical position of subjects (Sect. 2.3.1), the assumption that nahĩ: is NEG (19) leads us to reject the constituency in (20), with a left-adjoined negative nahĩ: c-commanded by the subject:

\footnotetext{
${ }^{15}$ Note that the ALWAYS $\gg \neg$ reading of (13) requires, if the NEG-above-Asp hypothesis is correct, that the subject DP Ram scrambles in a high position on the surface.
} 
Left-attachment:

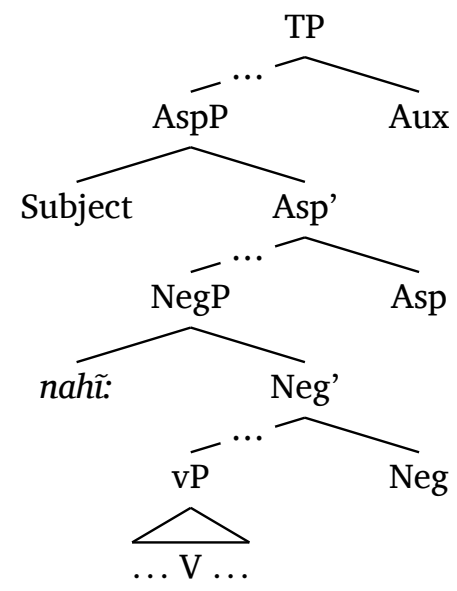

Regardless of the foregoing argument, left-attachment of nahĩ: is also incompatible with the wide scope of negation over the preceding adverb hameshaa (13) (nahĩ: cannot both be c-commanded by the adverb on the surface and outscope it, as adverbs and negation do not move covertly by hypothesis). Note that left-attachment above the subject position would not derive the surface order. We can thus write:

(21) Implication: If nahĩ: is semantically negative, then nahĩ: is not left-attached

(it is right-attached).

Equivalently (by contraposition):

If nahĩ: is left-attached, then nahĩ: is not semantically negative.

Under the hypothesis that nahĩ: is semantically negative, it is right-attached, with V rightward-moving around it (in the 'nahĩ: V' order):

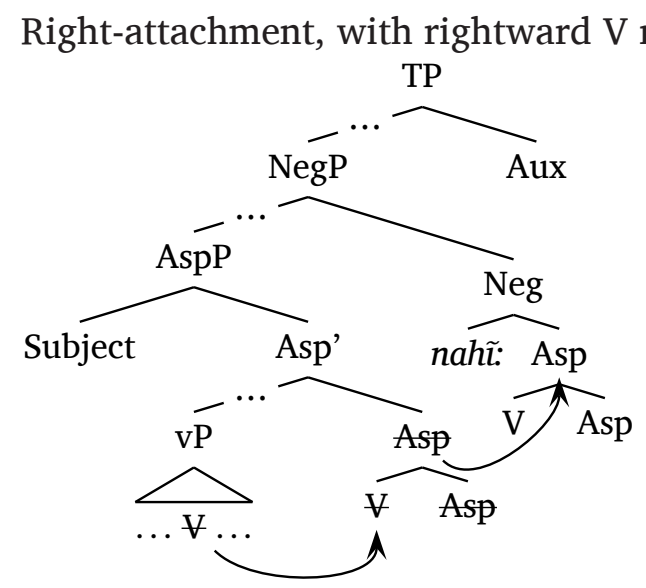

We propose that V forms a complex head with nahĩ: and the intermediate Asp, by head movement (Travis 1984; Koopman 1984; Baker 1985; 1988; Harizanov \& Gribanova 2019). Tree (22) has nahĩ: as the head of NegP, ${ }^{17}$ rather than as a phrase in the specifier of NegP.

\footnotetext{
${ }^{16}$ Note that (22) is a surface tree although we arrived at it using scope facts: by hypothesis, neither negation nor adverbs move at LF, so we can deduce their position on the surface from their interpretation position.

${ }^{17}$ We are not certain that V doesn't head-move higher than nahĩ. Another decision is worth mentioning, which is justified by the key observation discussed in this article (Sects. 3.2.1 and 4): we show head-movement to the right of nahĩ: and head-movement to the left of all other heads, as required by the observed surface order.
} 
The existence of non-clausal right specifiers in the language is dubious or controversial, therefore we treat nahĩ: as a head. In the unmarked order at least, nahĩ: has to be adjacent to V (4) (see also Kumar 2006: ex. (38a)). We take this to indicate that nahĩ: and V form a complex head, via head movement, resulting in an inverted order (following Kumar 2006). Strict adjacency supports the constituency shown in (22), regardless of whether nahĩ: is negative or not. ${ }^{18}$

Our argument that NEG sits above the canonical position of subjects leads us to conclude that this canonical position is probably not Spec,TP. This is because auxiliaries are ordered after nahĩ., i.e., NEG, on the surface, and are thus higher than NEG; if we assume that auxiliaries are in $\mathrm{T}$, then the canonical position of subjects should be lower than $\mathrm{T}$, hence our assumption that it is Spec,AspP. ${ }^{19}$

In sum, we have established the following. (i) Whether Assumption (19) is correct or not (i.e., whether nahĩ: is NEG or not), NEG must sit higher than the canonical surface position of subjects in Hindi-Urdu (of course, subjects can scramble past this position) (Sect. 2.3.1). And (ii) if Assumption (19) is correct, i.e., the negative marker is indeed semantically negative, then it must be attached to the right of vP, since it can outscope preceding adverbs and subjects in their canonical position (but surfaces after them), with the verb head-moving to it so as to derive the surface order 'nahĩ: V' (as shown in (22)) (Sect. 2.3.2):

(23) (i) If nahĩ: is semantically negative, then nahĩ: is right-attached.

(ii) If nahĩ: is right-attached, then the 'nahĩ: V' order is derived by rightward movement of $\mathrm{V}$ to nahĩ.

$\therefore \quad$ If nahĩ: is semantically negative, then the 'nahĩ: V' order is derived by rightward movement of $\mathrm{V}$ to nahĩ.

(Transitivity of $\Rightarrow$ )

In the next section, we discuss the exceptional behavior of seemingly embedded negation described in the Introduction: we show that this behavior only obtains in restructuring environments.

\section{Negation with complementation}

\subsection{Finite clauses}

Somewhat unsurprisingly, a negation in an embedded finite clause cannot license NPIs in the matrix clause. It also cannot license auxiliary deletion in the matrix clause:

*ek-bhii laṛke-ne kah-aa [ki Ram nahĩ: aa-yaa] one-even boy-ERG say-PFV that Ram NEG come-PFV.MSG Intended: 'Not even a single boy said that Ram came.'

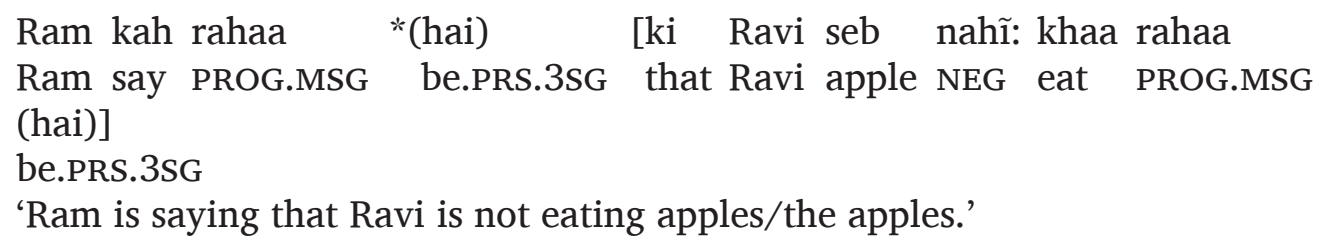

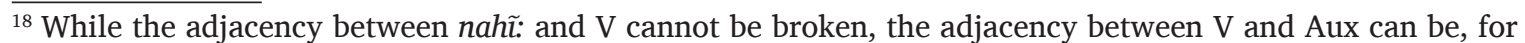
example by an object: this suggests to us that Aux need not form a morphological complex with V.

${ }^{19}$ Kumar (2006) also arrives at the conclusion that NEG, which he believes to be the same as nahĩ:, is above Asp; however he contends that subjects are higher than NEG in their canonical position. His argument, unlike ours, doesn't rely on scope relations.
} 
The behavior in the other direction is a bit more surprising. A matrix negation can license an NPI in an embedded clause but it cannot license auxiliary deletion in the embedded clause.

Ram-ko nahĩ: lag-taa (hai) [ki koi-bhii aa-egaa $]$

Ram-DAT NEG seem-HAB be.PRS that someone-even come-FUT.3MSG

'Ram doesn't think that anyone will come.'

Ram-ko nahĩ: lag-taa (hai) [ki Mina aajkal aisii kitaabẽ paṛh Ram-DAT NEG seem-HAB be.PRS that Mina these.days such.F books.F read rahii *(hai)]

PROG.F be.PRS.3SG

'Ram doesn't think that Mina is reading such books these days.'

Auxiliary deletion is thus a test of clausemate negation. NPI licensing is not such a test, but it still requires a negation that is higher than the NPI.

\subsection{Infinitival clauses: Restructuring vs. non-restructuring}

Some infinitival clauses present a paradox, which we already introduced at the beginning of this article: a negation which seems to be inside an infinitival complement has effects typical of a matrix negation.

\subsubsection{The paradox}

In (28) the negation that appears to be embedded licenses deletion of the matrix auxiliary, which in view of the foregoing discussion, requires a clausemate licenser:

(28) (Seemingly) embedded negation licenses matrix auxiliary deletion (Bhatt 2005):

Ram Mina-kii madad nahĩ: kar-naa caah-taa (hai)

Ram Mina-GEN.F help.F NEG do-INF want-HAB.MSG be.PRS.3sG

'Ram doesn't want to help Mina.'

In (29), the NPI requires a negation above it (this means, again, a matrix negation):

(29) (Seemingly) embedded negation licenses matrix NPI (Mahajan 1990):

ek-bhii larke-ne Mina-kii madad nahĩ: kar-nii caah-ii

one-even boy-ERG Mina-GEN.F help.F NEG do-INF.F want-PFV.F

'Not even a single boy wanted to help Mina.'

There are thus two hallmarks of the exceptional behavior of negation: (i) licensing of matrix NPIs and (ii) licensing of matrix auxiliary deletion, both by a (seemingly) embedded negation.

Note that it is possible to have the negative marker in a position where it is unambiguously in the matrix clause, i.e., right before the matrix verb $\left({ }^{\prime} \mathrm{V}_{1}\right.$ nahĩ: $\mathrm{V}_{2}$ ' order). NPI licensing and auxiliary deletion are, unsurprisingly, possible: ${ }^{20}$

(30) Matrix negation licenses matrix NPIs:

ek-bhii laṛke-ne Mina-kii madad kar-nii nahĩ: caah-ii

one-even boy-ERG Mina-GEN.F help.F do-INF.F NEG want-PFV.F

'Not even a single boy wanted to help Mina.'

\footnotetext{
${ }^{20}$ The resulting structures have the same meaning as the structures with a negation that seems to be inside the infinitival clause.
} 
(31) Matrix negation licenses matrix auxiliary deletion:

Ram Mina-kii madad kar-naa nahĩ: caah-taa (hai)

Ram Mina-GEN.F help.F do-INF NEG want-HAB.MSG be.PRS.3SG

'Ram doesn't want to help Mina.'

In addition to the two tests that diagnose the exceptional behavior, we note that it is quite odd to have both negations (the seemingly embedded one and the matrix one) at the same time. The result feels deviant (we will come back to this issue in Sect. 4.2):

(32) Two negations: ???

???Ram-ne Mina-kii madad nahĩ: kar-nii nahĩ: caah-ii

Ram-ERG Mina-GEN.F help.F NEG do-INF.F NEG want-PFV.F

Intended: 'Ram didn't want to not help Mina.'

A (non-exhaustive) list of verbs whose infinitival complements allow for the exceptional behavior of negation is shown in Table 1.

These verbs (e.g., want, have to, start, etc.) are restructuring predicates (as are their equivalents in many languages). ${ }^{21}$ 'Restructuring' is a term used to name a range of processes which, although they are ordinarily clause-bounded, can apply across non-finite clause boundaries. Restructuring is diagnosed by clitic climbing in Romance (Aissen \& Perlmutter 1983; Rizzi 1978 a.o.) and by long distance scrambling in Germanic (Wurmbrand 2001 a.o.). In Hindi-Urdu, restructuring complements have the following common characteristics: they typically appear as direct objects or internal arguments of the embedding predicate; they do not bear any overt case marking; Long Distance Agreement (LDA) is only possible out of these infinitives (Bhatt 2005). LDA can be described as the agreement of a verb with an argument that is not its own, provided that this verb has no non-overtly casemarked arguments of its own. We illustrate the phenomenon with (33) (Bhatt 2005: ex. (4)), where caah 'want' has an ergative subject (no non-overtly case-marked arguments of its own) and agrees with kitaab 'book', the object of the embedded verb:

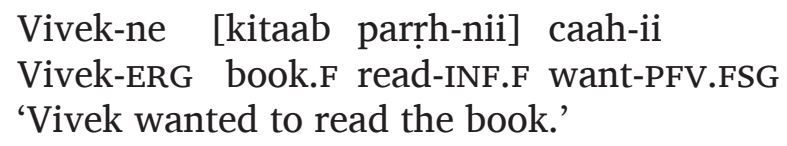

The following conjecture emerges from the foregoing discussion (also formulated by Bhatt (2005) and partly by Mahajan (1990)):

Table 1: Verbs that permit the exceptional behavior of negation.

\begin{tabular}{|l|l|l|}
\hline \multirow{3}{*}{ Modals } & sak-naa & 'can' \\
\cline { 2 - 3 } & caahiye & 'should' \\
\cline { 2 - 3 } & Dative+V-Inf+be & 'have to' \\
\cline { 2 - 3 } & par-naa & 'fall/had to' \\
\hline \multirow{2}{*}{ Aspectuals } & shuruu ho/kar-naa & 'start' \\
\cline { 2 - 3 } & V-ne vaalaa hai & 'be about to' \\
\hline \multirow{2}{*}{ Other } & caah-naa & 'want' \\
\cline { 2 - 3 } & Dative+V-Inf+come & 'know how to V' \\
\cline { 2 - 3 } & V-ne diyaa & 'let V' (permissive) \\
\hline
\end{tabular}

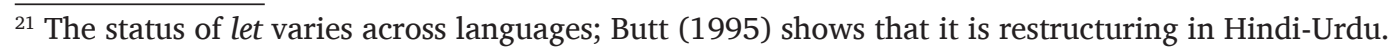


Conjecture: The exceptional behavior of negation, diagnosed by the licensing of matrix NPIs and the licensing of matrix Aux deletion by a (seemingly) embedded negation, is only possible in restructuring infinitives.

In the next subsection, we verify the conjecture by showing that non-restructuring infinitives are incompatible with the exceptional behavior of negation.

\subsection{2 'Opaque' (non-restructuring) infinitives}

Infinitival subjects do not permit the exceptional behavior of negation:

Embedded negation does not license auxiliary deletion:

[mehnat nahĩ: kar-naa] buraa ho-taa *(hai)

hard.work.F NEG do-INF bad be-HAB be.PRS.SG

'To not work hard is a bad thing.'

(36) Embedded negation does not license matrix NPIs:

*[mehnat nahĩ: kar-naa] katai acchaa ho-taa hai hard.work.F NEG do-INF a.bit good be-HAB be.PRS.SG

Intended: 'To not work hard is a tiniest bit good thing.'

Notice also that 'double negation', which is impossible with want (32), is possible here:

'Double negation' is ok:

[mehnat nahĩ: kar-naa] katai acchaa nahĩ: ho-taa hai hard.work.F NEG do-INF a.bit good NEG be-HAB be.PRS.SG

'To not work hard is not good in the least.'

Second, case-marked infinitival clauses are also incompatible with the exceptional behavior of negation:

(38) Embedded negation does not license auxiliary deletion:

Ram Mona-se [Dilli nahĩ: jaa-ne]-ko kah-taa *(hai)

Ram Mona-with Delhi NEG go-INF.OBL-DAT say-HAB be.PRS.SG

'Ram tells Mona to not go to Delhi.'

(39) Embedded negation does not license matrix NPIs:

*kisi-ne-bhii Mona-se [Dilli nahĩ: jaa-ne]-ko kah-aa someone-ERG-even Mona-with Delhi NEG go-INF.OBL-DAT say-PFV Intended: 'Someone told Mona to not go to Delhi.'

(40) 'Double negation' is ok:

Ram Mona-se [Dilli nahĩ: jaa-ne]-ko nahĩ: kah-taa (hai)

Ram Mona-with Delhi NEG go-INF.OBL-DAT NEG say-HAB be.PRS.SG

'Ram doesn't tell Mona to not go to Delhi.'

Certain non case-marked infinitives also do not allow for the exceptional behavior, for example the complement of bhuulaa 'forget':

(41) Ram [khịkii nahĩ: band karnaa] bhuul-taa *(hai)

Ram window.F NEG close do.INF forget-HAB be.PRS.SG

'Ram forgets to not close the window.' 
(42) Ram [khị̣kii band karnaa] nahĩ: bhuul-taa (hai)

Ram window.F close do.INF NEG forget-HAB be.PRS.SG

'Ram doesn't forget to close the window.'

(43) *ek-bhii laṛkaa [khị̣kii nahĩ: band karnaa] bhuulaa one-even boy window.F NEG close do.INF forget.PFV Intended: 'Not even one boy forgot to close the window.'

(44) ek-bhii laṛkaa [khị̣kii band karnaa] nahĩ: bhuulaa one-even boy window.F close do.INF NEG forget.PFV 'Not even one boy forgot to close the window.'

(45) 'Double negation' is ok:

ek-bhii laṛkaa [khiṛkii nahĩ: band karnaa] nahĩ: bhuulaa one-even boy window.F NEG close do.INF NEG forget.PFV 'Not even one boy forgot to not close the window.'

The verbs whose complements are incompatible with the exceptional behavior of negation (see Table 2) are all non-restructuring verbs. Non-restructuring complements have a common characteristic, namely, they do not permit LDA. ${ }^{22}$

(46) With LDA:

*mehnat kar-nii acchii ho-tii hai

hard.work.F do-INF.F good.F be-HAB.F is

Intended: 'To work hard is good.'

(47) Without LDA:

mehnat kar-naa acchaa ho-taa hai

hard.work.F do-INF.M good.M be-HAB.M is

'To work hard is good.'

The same pattern obtains in case-marked infinitives:
Ram-ne Mina-se [kitaab parhne-ko]
kahaa/ *kahii
Ram-ERG Mina-INS book.F read.INF.OBL-DAT say.PFV.M say.PFV.F
'Ram told Mina to read a/the book.'

Table 2: Verbs that don't permit the exceptional behavior of negation.

\begin{tabular}{|l|l|}
\hline V-Inf bhuul-naa & 'forget' \\
\hline V-Inf-Gen koshish kar-naa & 'try' \\
\hline V-Inf-Gen vaadaa kar-naa & 'promise' \\
\hline V-Inf-Dat kah-naa & 'say' \\
\hline V-Inf-for mazbuur kar-naa & 'force' \\
\hline V-naa band ho/kar-naa & 'stop' \\
\hline V-Inf-Gen faislaa kar-naa & 'decide' \\
\hline V-Inf-Gen dhamkii/anumati/aagyaa de-naa/gave & 'threaten/permit/order' \\
\hline
\end{tabular}

\footnotetext{
${ }^{22}$ Try is restructuring in German (Wurmbrand 2001); it is not in Hindi-Urdu if we trust that unavailability of LDA diagnoses non-restructuring; note that it is literally 'do an attempt of', with a genitive mark. Forget is restructuring in German and Japanese, but not in Hindi-Urdu, by the same criterion.
} 
We have now uncovered a second criterion of restructuring in Hindi-Urdu, namely the exceptional behavior of negation (only restructuring predicates permit it). The generalization that the exceptional scope of negation is only possible out of restructuring infinitives (and that LDA is also only possible out of such infinitives) was already formulated by Bhatt (2005). The fact that restructuring is a necessary condition (as stated by (34)) suggests an explanation, developed in the next section, for the exceptional behavior of negation: the embedded verb moves into the matrix to form a cluster with the main verb, and the cluster subsequently head-moves to nahĩ:, resulting in the 'nahĩ: $\mathrm{V}_{1} \mathrm{~V}_{2}$ ' order (i.e., a matrix negation that looks like an embedded one); this head movement out of the infinitive complement (which creates the ' $\mathrm{V}_{1} \mathrm{~V}_{2}$ ' cluster) is only possible in restructuring environments.

\section{Analysis}

In this section, we argue that infinitival complements in Hindi-Urdu provide a new example of verb clustering. We claim that an infinitival verb in this language can form a complex head with an adjacent embedding verb: this process is only possible out of a restructuring complement; a subsequent movement brings the complex head to the matrix nahĩ. The 'nahĩ: $\mathrm{V}_{1} \mathrm{~V}_{2}$ ' order coupled with matrix licensing effects (what we call 'exceptional behavior of negation') requires cluster formation: what we see in our example (1) is an infinitival verb forming a cluster with a matrix verb, and tagging along with the latter (see Haider 1993; 2010; 2003 on the role of verb clusters in restructuring in German). Negation thus allows us to detect verb cluster formation.

$$
\begin{aligned}
& \text { Seemingly embedded negation licenses a matrix NPI: } \\
& \text { ek-bhii larke-ne Mina-kii madad nahĩ: kar-nii caah-ii } \\
& \text { one-even boy-ERG Mina-GEN.F help.F NEG do-INF.F want-PFV.F } \\
& \text { 'Not even a single boy wanted to help Mina.' }
\end{aligned}
$$

$$
\left[_{\text {Main }} \text { Subject } \ldots\left[_{\text {Embedded }} \ldots \forall_{7}\right] \forall_{z} \text { nahĩ: }\left[\mathrm{V}_{1}-\mathrm{V}_{2}\right] \text { Aux }\right]
$$

Note that the rightward verb movement process that creates the complex head is stringvacuous - the underlying order of the embedded verb and the matrix verb $\left(\mathrm{V}_{\text {embed }}>\right.$ $\left.\mathrm{V}_{\text {matrix }}\right)$ is preserved by verb movement $\left(\mathrm{V}_{\text {embed }}+\mathrm{V}_{\text {matrix }}\right)$. This is in contrast to the process that moves the verb to nahĩ: where the underlying order $(\mathrm{V}>$ nahĩ: $)$ is reversed yielding nahĩ: > V.

In the following, we verify the claim that the exceptional behavior requires matrix negation and hence cluster formation, as in (50). And then we justify the link we made between exceptional behavior and restructuring (Conjecture (34)) and discuss the implications this has for the theory of restructuring.

\subsection{The exceptional behavior requires cluster formation}

To confirm that when negation behaves exceptionally, it is in the matrix clause and consequently, cluster formation is needed, the predicate shuruu kar 'start do' ('start') will be our test case, because it is a restructuring verb but unlike caah, it is not a neg-raising predicate, and thus allows us to use the scope of negation as an indicator of its position (with caah, neg-raising creates a confound because, whether negation is the embedded or in the matrix, it ends up being interpreted with narrow scope w.r.t. the embedding attitude; on neg-raising, see Fillmore 1963; Bartsch 1973; Horn 1989; Gajewski 2007; Collins \& Postal 2017 a.o. and the Appendix to this article). 
nahĩ: adjacent to the matrix verb:

printer-ne abhi:-tak ka:m kar-na: shuru: nahĩ: kiya: hai printer-ERG now-till work do-INF start NEG do.PFV be.PRS.3SG

'The printer has not started working (yet).'

only: $\neg \gg$ START

The above example, where nahĩ: appears adjacent to the matrix verb (that is, where matrix negation is expected to be realized) can only be interpreted with the scope $\neg \gg$ START, showing that the predicate is not a neg-raiser. ${ }^{23}$ With start the 'nahĩ: $\mathrm{V}_{1} \mathrm{~V}_{2}$ ' order permits two construals (START» $\neg$ and $\neg \gg$ START), which can clearly be distinguished by the scope of negation: this verb thus offers useful controls. In the following example, we force the START $\gg \neg$ interpretation by putting a compound verb in the matrix clause which is independently incompatible with a clausemate negation (on compound verbs being Positive Polarity Items, see Hook 1974 and Homer \& Bhatt 2019):

nahĩ: adjacent to the embedded verb, with a matrix compound verb:

printer-ne ka:m nahĩ: kar-na: shuru: kar diya: hai printer-ERG work NEG do-INF start do give.PFV be.PRS.3SG 'The printer has started not working (again).' only: START》ᄀ

In the absence of such a compound verb, a nahi: that appears adjacent to the embedded verb can still yield the $\neg \gg$ START interpretation; this scopal relation requires a matrix negation:

(53) nahĩ adjacent to the embedded verb, without a matrix compound verb:

is mue printer-ne abhi-tak ka:m nahĩ: kar-na: shuru: kiyaa!

this damn printer-ERG now-till work NEG do-INF start do.PRS.3SG

'This damn printer has still not started working!'

$\checkmark \neg \gg$ START

Now, we can proceed to the second step: it is possible to show that the exceptional behavior only occurs with the $\neg \gg$ START reading of the 'nahĩ: $\mathrm{V}_{1} \mathrm{~V}_{2}$ ' order, that is, with a matrix negation. In (54), a subject NPI is licensed, and the only scopal relation between negation and the main verb is $\neg \gg$ START:

(54) koi-bhii sarkaar apne aap apne adhikaarõ-ko vikendrikrit nahĩ: kar-naa some-even government itself self's rights-DAT decentralize NEG do-INF shuruu kar-tii

start do-HAB.F

'No government starts decentralizing its powers on its own.' only: $\neg$ \START

When we force the negation to take scope under start (and thus be in the embedded clause) using a compound verb in the matrix, the negation is unable to license matrix NPIs (55a) or auxiliary deletion (55b):

With obligatory START $\gg \neg$ construal:

a. *ek-bhii printer [ka:m nahĩ: kar-na:] shuru: kar deta: hai one-even printer work NEG do-INF start do give.HAB be.PRS.3SG Intended: 'Some printer has started not working (again).'

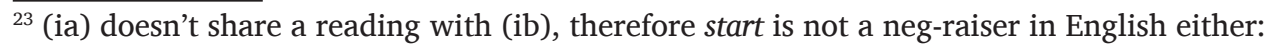

(i) a. The printer has not started working (yet).

b. The printer has started not working (again). 
b. printer [ka:m nahĩ: kar-na:] shuru: kar deta: *(hai)

printer work NEG do-INF start do give.HAB be.PRS.3SG

'The printer has started not working (again).'

We have thus confirmed that with the word order 'nahĩ: $\mathrm{V}_{1} \mathrm{~V}_{2}$ ', the exceptional licensing effects require the presence of negation in the matrix, despite appearances. It follows from our assumption that nahĩ is sentential negation (19) that moving the embedded verb is required to derive the 'nahi: $\mathrm{V}_{1} \mathrm{~V}_{2}$ ' order: the embedded verb piggy-backs on the matrix verb, which rightward-moves to nahĩ:, as normally happens in simplex clauses (see (22) on p. 14):

$$
\begin{aligned}
& \left.\mathrm{O} \mathrm{V}_{i}\right] \mathrm{V}_{j} \text { ] nahĩ: } \\
& \left.\left.\mathrm{O} \mathrm{t}_{i}\right]\left[\mathrm{~V}_{i}+\mathrm{V}_{j}\right]\right] \text { nahĩ: } \\
& \left.\left.\mathrm{Ot}_{i}\right] \mathrm{t}_{j}\right] \text { nahi: }\left[\mathrm{V}_{i}+\mathrm{V}_{j}\right]
\end{aligned}
$$

We submit that the two verbal heads form a complex head: this is what we call 'cluster formation' (after Keine \& Bhatt 2016).

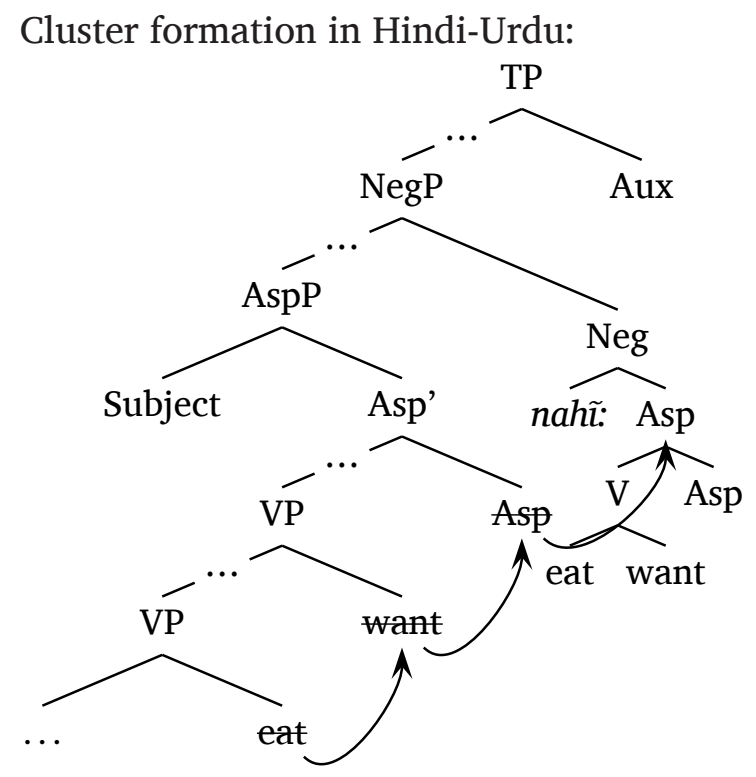

(58) Implication: If matrix licensing effects occur with the 'nahĩ: $\mathrm{V}_{1} \mathrm{~V}_{2}$ ' order, then (i) nahĩ: is in the matrix and hence (ii) there is verb cluster formation.

As a control, we show that when verb cluster formation is unequivocally absent (and negation is unequivocally embedded), then the matrix licensing effects become impossible (thus verifying the contraposition of (58)). Even though the infinitival verb is typically adjacent to the matrix verb, this adjacency can be disrupted, precluding verb cluster formation:

[ka:m kar-na:] printer-ne shuru: kar diya: hai work do-INF printer-ERG start do give.PFV be.PRS.3SG 'The printer has started working.'

We see that a nahi: adjacent to the infinitival verb is unable to license matrix NPIs or matrix auxiliary deletion if we disrupt adjacency: 
(60) Adjacency between V-Inf and V is disrupted, nahĩ: cannot have licensing effects in the matrix:

a. *[ka:m nahĩ: kar-na:] ek-bhii printer-ne shuru: kiyaa work NEG do-INF one-even printer-ERG start do.PFV Intended: 'No printer has started working.'

b. [ka:m nahĩ: kar-na:] printer do baje shuru: kartaa *(hai) work NEG do-INF printer two o'clock start do.IPFV be.PRS.SG 'The printer starts not working at 2 o'clock.'

Because the exceptional behavior of negation requires restructuring (Sect. 3.2), we can conclude that verb clustering, as diagnosed by the placement of the marker nahĩ: (i.e., the 'nahĩ: $\mathrm{V}_{1} \mathrm{~V}_{2}$ ' order) under a wide scope construal of negation, only happens if the embedded clause is a restructuring infinitive.

(61) Implication: If $\mathrm{V}_{\text {embed }}+\mathrm{V}_{\text {matrix }}$ clustering obtains, then the complement is restructuring.

We don't observe the exceptional behavior with non-restructuring predicates, as shown by (38)-(39). We showed lack of licensing effects in the matrix under the order 'nahĩ: $\mathrm{V}_{1} \mathrm{~V}_{2}$ '; we now add to this the obligatory narrow scope of negation under the same order:

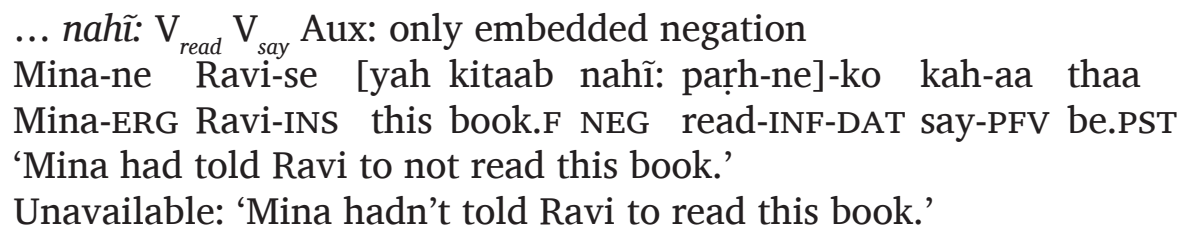

In the next subsection, we show that shuruu kar 'start' differs from other restructuring embedding verbs, e.g., sak 'can', with which the 'nahĩ: $\mathrm{V}_{1} \mathrm{~V}_{2}$ ' order is not scopally ambiguous, i.e., is only compatible with a high negation interpretation. We argue that under the low negation construal of the 'nahĩ: $\mathrm{V}_{1}$ start' order, shuruu kar 'start' is not restructuring. Therefore some verbs are part-time restructuring verbs.

\subsection{Differences among restructuring complements}

With the verb sak 'can', another restructuring verb, the order 'nahĩ: $\mathrm{V}_{1}$ can' only delivers one reading, $\neg \gg$ CAN:
Ram tiis
second-tak saans nahĩ: le
saktaa
hai
Ram thirty seconds-till breath NEG take can.HAB.MSG be.PRS.SG
'Ram can't breathe for 30 seconds.'
Unavailable: 'Ram has the ability to not breathe for 30 seconds.'

$\checkmark \neg \gg \mathrm{CAN}$

$* \mathrm{CAN} \gg \neg$

This suggests that the complement of sak cannot host a negation, which in turns suggests that it is too small for that (in Sect. 4.4 we propose that it is vP): ${ }^{24}$ then for nahĩ: to precede $\mathrm{V}_{1}, \mathrm{~V}_{1}$ has to form a cluster with can, which moves further along (the 'nahĩ: $\mathrm{V}_{1}$ can' order cannot result from movement of $\mathrm{V}_{1}$ to an embedded nahĩ). Furthermore, the order ' $\mathrm{V}_{1}$ nahĩ: can' is also possible, and it again only has the $\neg \gg \mathrm{CAN}$ reading:

\footnotetext{
${ }^{24}$ We use semantic criteria, e.g., scope w.r.t. the embedding verb, to diagnose the presence of negation in the embedded clause; we propose that certain infinitival complements are truncated below the position of negation. Specifically, we make the claim, at the end of this subsection, that only non-restructuring complements can host embedded negation. A parallel claim is made about Italian by Cardinaletti \& Shlonsky (2004), who observe that embedded negation blocks restructuring, as diagnosed by clitic climbing and auxiliary switch; they propose that the presence of negation implies the projection of a full $\mathrm{CP}$, which by its very size is non-restructuring.
} 

Ram tiis second-tak saans le nahĩ: saktaa
hai
Ram thirty seconds-till breath take NEG can.HAB.MSG be.PRS.SG
'Ram can't breathe for 30 seconds.'
$\checkmark \neg \gg$ CAN
Unavailable: 'Ram has the ability to not breathe for 30 seconds.'
$* \mathrm{CAN} \gg \neg$

By itself, the availability of two word orders doesn't tell us that cluster formation is optional. We submit that it is obligatory when possible, and that the configuration that allows it is sometimes missing, for example when the infinitival clause is moved as in (59). Phrasal movement happens before $V$ movement and can thus bleed it. Danish offers examples of bleeding of V movement: VP topicalization and VP ellipsis result in do-support, not in ungrammaticality (Houser et al. 2011; Gribanova \& Mikkelsen 2018). ${ }^{25}$ The failure to form a complex head doesn't lead to ungrammaticality, since neither $\mathrm{V}$ is a bound morpheme (morphologydriven $\mathrm{V}$ movement on the other hand, e.g., V-to-Asp, cannot fail to happen without causing a crash). To account for the ' $\mathrm{V}_{1}$ nahĩ: can' order, we thus propose that the infinitival complement of can can move string-vacuously; when it does, verb clustering becomes impossible, resulting in that order (more on this in Sect. 4.4). Similarly, string-vacuous movement of AspP can explain the marked order 'V nahĩ: Aux' (2b) in simplex clauses. ${ }^{26}$

The complement of want also seems to be too small to host a negation. This is shown by the degradation of sentences like (32): the second negation is unequivocally in the matrix and the first one, by virtue of the ban on multiple clausemate negations (5), must be in the embedded clause: ${ }^{27}$

(65) ???Ram-ne Mina-kii madad nahĩ: kar-nii nahĩ: caah-ii

Ram-ERG Mina-GEN.F help.F NEG do-INF.F NEG want-PFV.F

Intended: 'Ram didn't want to not help Mina.' [ $\quad$ (32)]

We can rule out the possibility that (65) is odd because caah 'want' is a neg-raising predicate. This is because double negation is acceptable when caah takes a finite clause complement, as in (66), which allows for a neg-raised interpretation where Ram is against Mina's not going to Delhi, as opposed to just being indifferent.

$$
\begin{aligned}
& \text { Ram nahĩ: caah-taa }[\mathrm{ki} \text { Mina Dilli nahĩ: jaa-e }] \\
& \text { Ram NEG want-HAB that Mina.F Delhi NEG go-SBJV.3.SG } \\
& \text { 'Ram doesn't want that Mina not go to Delhi.' }
\end{aligned}
$$

Turning to start, its complement can obviously contain a negation (52). And double negation is possible:

$$
\begin{aligned}
& \text { printer-ne abhi:-tak [ka:m nahĩ: kar-na:] shuru: nahĩ: kiya: hai } \\
& \text { printer-ERG now-till work NEG do-INF start NEG do.PFV be.PRS.SG } \\
& \text { 'The printer hasn't started not working up until now.' } \\
& \checkmark \neg \gg S T A R T \gg \neg
\end{aligned}
$$

We propose that its infinitival complement can be larger than the infinitival complement of can. We distinguish two main analytical options. (i) Each restructuring verb has

\footnotetext{
$\overline{{ }^{25} \text { Compare with: }}$

(i) a. *Be nice, he did.

b. Mary was nice but he didn't.

${ }^{26}$ The word order 'V Aux nahĩ:' (2c) is not only marked, it has very different conditions of use. There nahĩ: negates a thought or a statement salient in context. It may be a different object than the 'regular' sentential negation.

${ }^{27}$ Remember that with want, we can't use scope to determine the position of negation, because want is a neg-raiser.
} 
an infinitival complement with a fixed size, but restructuring verb complements are not equal among themselves; not all restructuring complements are large enough to encompass the position of negation (in Hindi-Urdu, the complement of start, unlike that of can or want, is large enough to contain negation). Or (ii) whether they vary in size or not, restructuring complements are all too small to host negation; and start in Hindi-Urdu is only optionally restructuring (qua restructuring verb, its complement is small; it is not restructuring when its complement contains a negation ${ }^{28}$ ).

It seems more economical to state, in agreement with the second horn of the alternative, that all restructuring complements are too small to host negation; and that the cases where the order 'nahĩ: $\mathrm{V}_{1}$ start' has a narrow scope reading of negation are cases where the complement is not restructuring. Our claim that negation is unavailable in restructuring complements (option (ii)) leads to a prediction: in accordance with (61), in the presence of an embedded negation, verb cluster formation is blocked (and the subsequent movement of the complex head to matrix nahĩ: is too). For concreteness' sake, the order 'nahĩ: nahĩ: $\mathrm{V}_{1}$ start' (derived as in (68)) is predicted to be impossible:

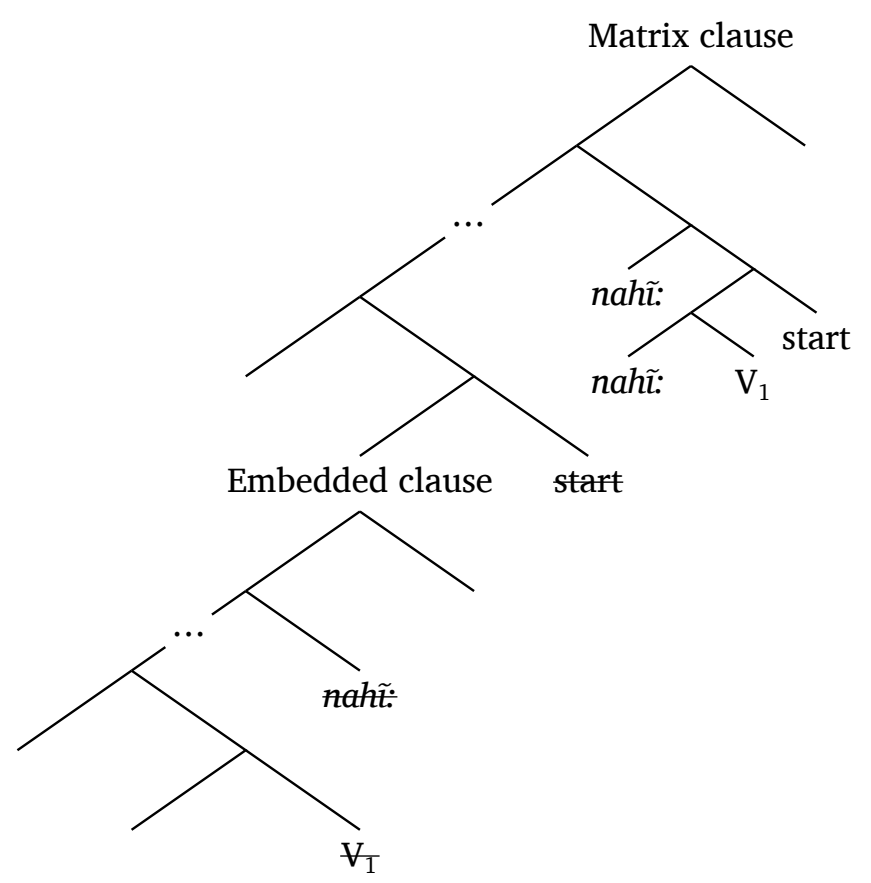

This is indeed what we find (compare with (67)):

*printer-ne abhi:-tak ka:m nahĩ: nahĩ: kar-na: shuru: kiya: hai printer-ERG now-till work NEG NEG do-INF start do.PFV be.PRS.SG Intended: 'The printer hasn't started not working up until now.'

In the next subsection, we add evidence in favor of the claim that start in Hindi-Urdu is not restructuring when its complement contains a negation. The overarching idea is that restructuring infinitives are too small to contain negation. Another diagnostic that has

$\overline{{ }^{28} \text { Double negation }}$ is possible under the order 'nahĩ: $\mathrm{V}_{1} \mathrm{~V}_{2}$ ' with $k a h$ 'say', which is never restructuring:

(i) ... nahĩ: $\mathrm{V}_{\text {read }}$ nahĩ: $\mathrm{V}_{\text {say }}$ Aux: ok

Mina-ne Ravi-se [yah kitaab nahĩ: paṛh-ne]-ko nahĩ: kah-aa thaa

Mina-ERG Ravi-INS this book.F NEG read-INF-DAT NEG say-PFV be.PST

'Mina hadn't told Ravi to not read this book.'

Each of the two negations has its own clause to negate. 
been argued to be associated with restructuring in Hindi-Urdu, namely Long Distance Agreement (LDA), helps us substantiate this claim.

\subsection{LDA, negation and restructuring}

There is one environment where we find an interaction between Long Distance Agreement and the size of the infinitival complement. Recall that we have argued that restructuring infinitives cannot host negation, i.e., negation cannot take scope inside them. So if we have an infinitival clause that includes negation which takes scope inside it, then we can reason that we do not have a restructuring infinitive. And in this case, Long Distance Agreement should be blocked, since LDA requires restructuring. This is indeed a correct prediction. In environments where negation stays downstairs, we don't get Long Distance Agreement; or at least it's degraded:

(70) Negation takes scope inside infinitival, no LDA:

Ram-ne [phir-se mehnat nahĩ: karnaa] shuruu kar diyaa

Ram-ERG again hard.work.F NEG do.INF.DEF start do give.PFV.DEF

thaa

be.PST.DEF

'Ram has again started to not work hard.'

(71) Negation takes scope inside infinitival, LDA: */degraded

???Ram-ne [phir-se mehnat nahĩ: karnii] shuruu kar dii thii

Ram-ERG again hard.work.F NEG do.INF.F start do give.PFV.F be.PST.F

Intended: 'Ram has again started to not work hard.'

When negation displays the exceptional behavior, both Long Distance Agreement and default agreement are possible:

(72) Negation takes scope outside infinitival: Long Distance Agreement possible ek-bhii larke-ne abhi-tak mehnat nahĩ: karnii shuruu kii one-even boy-ERG now-till hard.work.F NEG do.INF.F start do.PFV.F hai

be.PRS.DEF

'Not even one boy has started working hard yet.'

(73) Negation takes scope outside infinitival: default agreement possible ek-bhii laṛke-ne abhi-tak mehnat nahĩ: karnaa shuruu kiyaa one-even boy-ERG now-till hard.work.F NEG do.INF.DEF start do.PFV.DEF hai

be.PRS.DEF

'Not even one boy has started working hard yet.'

Our claim that negation in the infinitival complement is incompatible with restructuring has now been successfully tested twice. With (68)-(69) (Sect. 4.2), we showed that the presence of negation in the infinitival complement blocks verb clustering (a plausible explanation is that restructuring, a necessary condition for verb clustering per Implication (61), is missing). We have now verified the prediction that a downstairs negation also blocks LDA, which requires restructuring as well.

\subsection{The independence of verb clustering and Long Distance Agreement}

In this article, we have considered two restructuring diagnostics for Hindi-Urdu: verb clustering and Long Distance Agreement. We want to highlight here that these two diagnostics are independent. You can have one without the other. 
First we have cases where the exceptional behavior of negation tells us that verb movement has taken place, and both Long Distance Agreement and default agreement are possible:

(74) Verb clustering and LDA:

ek-bhii larke-ne roții nahĩ: khaanii caahii

[cf. (72)]

one-even boy-ERG bread.F NEG eat.INF.F want.PFV.F

'Not even a single boy wanted to eat bread.'

(75) Verb clustering and default agreement (no LDA):

ek-bhii laṛke-ne roții nahĩ: khaanaa caahaa

one-even boy-ERG bread.F NEG eat.INF.DEF want.PFV.DEF

'Not even a single boy wanted to eat bread.'

Verb clustering is possible, even when LDA doesn't take place (75).

Second, we can consider environments where the non-adjacency of the embedded verb and the matrix verb tells us that verb movement has not taken place. LDA is still possible:

(76) LDA and no verb clustering (scrambled infinitive):

[yeh kitaab parhnii] Ram-ne caahii thii

this book.F read.INF.F Ram-ERG want.PFV.F be.PST.F

'It was Ram who wanted to read this book.'

Note that we can also find cases where neither verb clustering nor LDA obtains:

(77) Scrambled infinitive, default agreement:

[yeh kitaab parhnaa] Ram-ne caahaa thaa

this book.F read.INF.DEF Ram-ERG want.PFV.DEF be.PST.DEF

'It was Ram who wanted to read this book.'

When the embedded infinitive is scrambled-the configuration for verb clustering is no longer available and V movement is bled-LDA is not disrupted. A way to derive this is to assume that agreement takes place before VP movement, in line with current conceptions in which a probe agrees as soon as it is merged with its complement (Béjar \& Rezac 2009).

(78) is more surprising as it shows us that even in an underlying configuration ' $\left.\left.\mathrm{V}_{1}\right] \mathrm{V}_{2}\right]$ nahĩ:', without scrambling, the embedded verb doesn't always move to the matrix verb: we propose that string-vacuous movement of the infinitival complement bleeds cluster formation (cf. Sect. 4.2).

LDA and no verb clustering $\left(\mathrm{V}_{1}\right.$ nahĩ: $\left.\mathrm{V}_{2}\right)$ :

Ram-ne [yeh kitaab paṛhnii] nahĩ: caahii thii

Ram-ERG this book.F read.INF.F NEG want.PFV.F be.PST.F

'Ram didn't want to read this book.'

We see again that LDA is possible even when clustering doesn't take place. Note that default agreement is also possible:

(79) $\mathrm{V}_{1}$ nahĩ: $\mathrm{V}_{2}$, default agreement:

Ram-ne [yeh kitaab parhnaa] nahĩ: caahaa thaa

Ram-ERG this book.F read.INF.DEF NEG want.PFV.DEF be.PST.DEF

'Ram didn't want to read this book.' 
Summing up, Long Distance Agreement and verb clustering are independent of each other. This independence raises an analytical challenge for approaches to Long Distance Agreement such as Bhatt 2005 and Keine 2016, which relate the optionality of Long Distance Agreement (see also Mahajan 1989 and Butt 1995) with caah 'want' to the idea that caah is optionally restructuring. Following Wurmbrand (2001), Keine's (2016) implementation of this optionality involves complements of varying sizes. For him, caah 'want' can embed either a vP (a restructuring complement), where LDA is obligatory (80), or a TP (a nonrestructuring complement), where LDA is impossible (81) (examples from Mahajan 1989):

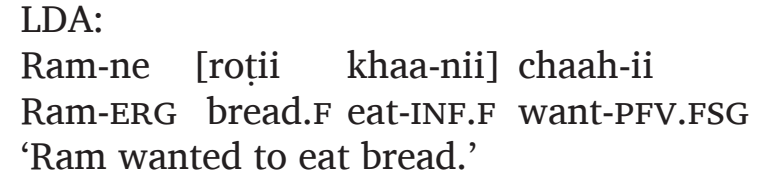

\section{No LDA: \\ Ram-ne [rotii khaa-naa] chaah-aa \\ Ram-ERG bread.F eat-INF.M want-PFV.MSG \\ 'Ram wanted to eat bread.'}

This line of reasoning leads one to expect that when verb clustering, which requires restructuring as shown in this article, happens, LDA should obligatorily obtain. But as we have seen, this prediction is not borne out. While Long Distance Agreement is indeed possible when the placement of negation (together with matrix licensing) signals verb movement, default agreement is also possible (see (75)).

The seeming challenge we believe comes from a simplistic on/off view of restructuring. Based on an examination of 23 typologically unrelated languages, Wurmbrand (2014; 2015) argues against such a view. She focuses on three restructuring diagnostics: long object movement, clitic climbing and scrambling, showing that these do not always travel together. In particular, she shows that in Chamorro, Czech, German, and Kannada a.o., [ + Future] infinitives permit clitic climbing and scrambling but not long object movement. In other words, [+ Future] infinitives are 'restructuring' or not depending upon which diagnostic we use. She contrasts [+Future] infinitives with [-Tense] infinitives, which in these languages permit all three movements. One component of her explanation is size-based restructuring. Suppressing a number of details, Wurmbrand proposes that infinitival complements may be of varying sizes: vP, TP or CP. Certain verbs will only combine with a specific size, others might combine with more than one size.

We use her insight to model the independence of Long Distance Agreement within Keine's system. To Keine's vP and TP, we add an intermediate projection, AspP. ${ }^{29}{ }_{\mathrm{vP}}$ is transparent to both Long Distance Agreement and verb clustering while AspP is transparent to verb clustering but opaque for LDA. TP is opaque to both. TP can include negation while AspP and vP are too small to host negation. There is one independent difference between Long Distance Agreement and verb clustering that is relevant here: Long Distance Agreement is not bled by movement of the infinitival complement while verb clustering is. We take this to be a matter of timing: agreement takes place before phrasal movement while $\mathrm{V}$ movement (hence cluster formation) happens after phrasal movement. Both operations are obligatory if possible but the difference in their timing means that phrasal movement can destroy the configuration for verb cluster formation but not for agreement. Moreover the possibility of string-vacuous verb projection movement means

\footnotetext{
${ }^{29}$ Aspect is not explicitly expressed in Hindi-Urdu infinitival clauses. But its presence can be motivated on semantic grounds following Pancheva \& von Stechow (2004) a.o.
} 
that even when we have a projection that in principle allows for verb cluster formation, vacuous movement of the verb projection can destroy the environment for this movement and make it in effect optional. ${ }^{30}$

Let us consider the full set of cases that we used to demonstrate the independence of Long Distance Agreement and verb clustering with the verb want (Table 3). Contra Keine, we argue that want in Hindi-Urdu does not combine with a full TP complement as we take TP to allow for negation, and the complement of want doesn't (65). We do have a predicate, start, which we believe allows for all three options: vP, AspP, and TP. The TP option allows for embedded negation and we have shown in (71) that embedded negation blocks LDA. Finally we believe we also have predicates that only allow for vP complements, e.g., the modal verbs, sak 'can', caahiye 'should' and the Hindi-Urdu equivalent of have to-LDA is obligatory with these.

The cut we find here (Table 4) is reminiscent of the cut between functional restructuring and lexical restructuring discussed in Wurmbrand 2001.

\subsection{Comparison with Mahajan 1990}

Mahajan (1990) argues that negation in Hindi-Urdu (identified with nahĩ:) is at the right of vP on the surface (V rightward-moves past it on its way to Agr), ${ }^{31}$ lower than the canonical position of subjects. It raises covertly at LF to a position where it c-commands and thus licenses subject NPIs (it adjoins to IP). Mahajan notices the paradox that we analyze in this article, namely the fact that a negation that precedes an infinitival verb can license an NPI

Table 3: Four options with want in Hindi-Urdu.

\begin{tabular}{|l|l|}
\hline LDA, verb clustering (74) & The infinitival complement is a vP and it has not undergone movement. \\
\hline LDA, no verb clustering ((76) \& (78)) & $\begin{array}{l}\text { The infinitival complement is a VP and it has undergone (possibly } \\
\text { string-vacuous) movement. }\end{array}$ \\
\hline No LDA, verb clustering (75) & The complement is an AspP and it has not undergone movement. \\
\hline No LDA, no verb clustering ((77) \& (79)) & $\begin{array}{l}\text { The complement is an AspP and it has undergone (possibly } \\
\text { string-vacuous) movement. }\end{array}$ \\
\hline
\end{tabular}

Table 4: Size-based classification of restructuring predicates in Hindi-Urdu.

\begin{tabular}{|l|l|l|}
\hline \multirow{4}{*}{ VP only } & sak-naa & 'can' \\
\cline { 2 - 3 } & caahiye & 'should' \\
\cline { 2 - 3 } & Dative+V-Inf+be & 'have to' \\
\cline { 2 - 3 } & par-naa & 'fall/had to' \\
\cline { 2 - 3 } & V-ne vaalaa hai & 'be about to' \\
\hline \multirow{2}{*}{ VP or AspP } & caah-naa & 'want' \\
\cline { 2 - 3 } & V-ne divaa & 'let V' (permissive) \\
\hline \multirow{2}{*}{ VP, AspP or TP } & shuruu ho/kar-naa & 'start' \\
\cline { 2 - 3 } & Dative+V-Inf+come & 'know how to V' \\
\hline
\end{tabular}

\footnotetext{
${ }^{30}$ We locate the source of apparent optionality of $\mathrm{V}$ movement in the existence of another movement, a phrasal one: the latter has a bleeding effect on the former. Postulating this string-vacuous movement allows us to maintain that Hindi-Urdu verb clustering is mandatory when possible, like its German counterpart, as described by Keine \& Bhatt (2016) (see Sect.6): in German, clustering only fails when the infinitival complement is moved. In German though, there is no air of optionality, and thus no string-vacuous movement of the complement needs to be stipulated. We do not know why such a movement would be possible in one language but not in another. We thank a Glossa reviewer for pressing us to clarify our motivations for postulating a string-vacuous movement.

${ }^{31}$ Mahajan is agnostic about whether the marker is a head or a phrase.
} 
subject in the matrix (p. 341). He claims that the 'nahĩ: $\mathrm{V}_{\text {embed }} \mathrm{V}_{\text {matrix }}$ ' order indicates that negation is in the infinitival complement: it raises covertly out of it and can thus license matrix NPIs. This cross-clausal movement is only possible out of restructuring complements: other long-distance dependencies, he claims, are also restricted to restructuring complements, namely wide scope of in situ wh-words, long distance reflexives, ${ }^{32}$ and LDA. The proposal is not fully articulated, but we can examine how an extension of it could handle the wider range of facts that we describe in this article. Note that we do not agree with the contention that the 'nahĩ: $\mathrm{V}_{\text {embed }} \mathrm{V}_{\text {matrix }}$ ' order entails that nahĩ: is in the embedded clause; but the two proposals, ours and our extension of Mahajan's, are similar in that they invoke a certain movement, restricted to certain environments (overt $\mathrm{V}$ movement vs. covert raising of negation).

The extension of Mahajan 1990 could put down the impossibility to interpret negation in the complement of certain restructuring verbs (see the evidence for sak 'can' in (63)-(64), and for caah 'want' in (65)) to the size of the complement: if the movement of negation targets a particular position in the tree, which is absent from truncated infinitival complements, then it is expected that it should proceed into the matrix to reach the closest available landing site. Regarding the lack of matrix licensing effects when the adjacency between V-Inf and matrix V is disrupted (60), the proposal could say that covert raising of negation out of a moved constituent is impossible (cf. Read every book some boy did, which only has a SOME»EVERY reading).

Be it as it may, covert movement of negation is, in and of itself, a costly hypothesis. Outside of Hindi-Urdu, we don't see that negation shows the scope flexibility that the hypothesis predicts. Just considering English, the position of not is not free and there is no evidence that it can raise covertly: consider the following sentences (the same case can easily be made about other languages):

$$
\begin{aligned}
& \text { a. John is not able to sing. } \\
& \text { b. John is able to not sing. }
\end{aligned}
$$

only: $\neg \gg \mathrm{ABLE}$

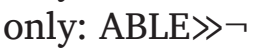

(82a) and (82b) do not have any reading in common, although the complement of the modal is permeable to $\mathrm{QR}$. Able is a control predicate, so the inverse scope reading requires $\mathrm{QR}$ of the lower QP in (83):

At least one American tourist is able to visit every European country this year.

$\checkmark$ EVERY $\gg$ AT_LEAST_ONE [Iatridou \& Sichel 2015]

In case one wonders whether not in (82b) is a different kind of negation, viz. constituent negation, we replicate the test in French, where the presence of the clitic ne is an indicator of a clausemate sentential negation: again, the two sentences have no reading in common: ${ }^{33}$

French:

a. Jean n'est pas capable de chanter.

Jean NE-is PAS able of sing

'Jean is not able to sing.'

only: $\neg \gg \mathrm{ABLE}$

b. Jean est capable de ne pas chanter.

Jean is able of NE PAS sing

'Jean is able to not sing.'

only: ABLE》ᄀ

\footnotetext{
32 These two points are in fact empirically incorrect: Dayal (1996) provides examples of wide scope wh out of non-restructuring environments, for example, ex. (21c) on p. 29 and ex. (28b) on p. 33. Also incorrect is the point about reflexives, see Davison 2001: ex. (1b).

${ }_{33}$ The inverse scope test (83) can also be replicated in French.
} 
In Hindi-Urdu, there is no independently attested example of the kind of scope reversing operation invoked by Mahajan. According to his hypothesis, covert raising of negation only takes place clause-internally or out of restructuring environments. One operation which is widely taken to involve covert movement in Hindi-Urdu, that is, wide scope of in situ wh-words, is not limited to restructuring environments (fn. 32). It is also expected that if negation can raise past the position of subjects covertly, then quantifiers should be able to do so too. (85) shows that this is not the case:

kisi: larke-ne har larki:-se baat ki:

some boy-ERG every girl-INS talk.F do.PFV.F

'Some boy talked to every girl.'

$\exists \gg \forall ; * \forall \gg \exists$

Some boy talked to every girl.

$\exists \gg \forall ; \forall \gg \gg \exists$

According to us, an infinitival $\mathrm{V}$ can piggy-back on a matrix $\mathrm{V}$ that raises to negation. Our account exploits V movement, a mechanism that was argued for by Kumar (2006) on independent grounds (and is compatible with Mahajan's account). ${ }^{34}$ We show that a coherent picture can be built where negation is sufficiently high on the surface to c-command the canonical position of subjects (Spec,AspP): therefore, given the hypothesis shared by Mahajan and us that nahĩ: is right-attached, covert raising of negation is not strongly motivated in simplex clauses in the first place.

Another argument against a Mahajan inspired account comes from Joshi (2019), who discusses the behavior of negation in Surati Gujarati. In this language, the environments where we find auxiliary deletion in the presence of negation in Hindi-Urdu display negated auxiliaries. And we find that the exceptionally scope-taking negation before infinitive verbs that has been the subject of discussion in this paper is realized by the appropriate negated auxiliary in auxiliary deletion environments. In other words, the form of the negation putatively inside the infinitival clause is determined by the matrix tense. This pattern is precisely what is predicted by our proposal - the seemingly embedded negation in our proposal is in the matrix and so we expect it to surface as a negated auxiliary if that is what the matrix environment demands. But it is not at all obvious that this pattern could be handled by a Mahajan inspired account. The negation under that proposal is only in the matrix clause at LF and it would be odd if the tail of a covert movement chain displayed features of a distinct element in the matrix clause.

Surati Gujarati (glosses ours):

a. ek-pan chokro skul nathi/ *nahi java maangto one-even boy school NEG.PRS NEG go.INF want 'Not even a single boy wants to go to school.'

b. ek-pan chokro skul nhoto/ *nahi java maangto one-even boy school NEG.PST NEG go.INF want 'Not even a single boy wanted to go to school.'

\section{What if nahĩ: is not negative?}

Our argumentation so far rests on the assumption that nahĩ: is intrinsically negative (19). We should now explore the implications of the opposite assumption, that nahĩ is not negative. A number of researchers claim that, in some languages, sentential negation is or can be a silent morpheme (Laka 1990; Ladusaw 1992; Rowlett 1998; Alonso-Ovalle

\footnotetext{
${ }^{34}$ Kumar (2006) briefly discusses the licensing of NPIs by a seemingly embedded negation; he gives a very preliminary treatment of the puzzle on p. 172.
} 
\& Guerzoni 2004; Zeijlstra 2008; Penka 2010; Homer \& Thommen 2013 a.o.). Abstract negation is postulated, for example, to account for the apparent negative strength of preverbal neg-words in non strict negative concord languages, e.g., Spanish and Italian (e.g., nessuno è venuto 'no one came' in Italian, where nessuno is a neg-word). The presence of the abstract negation is signaled by dedicated overt morphemes, specifically neg-words (or one could say, along the lines of Ladusaw 1992, that abstract negation needs to be licensed by neg-words). We could hypothesize that negation in Hindi-Urdu is covert and that nahĩ: is either a minimizer, whose meaning is akin to at all, or some more neutral element akin to in any way. Historically, pas in French (which Homer \& Thommen 2013 show to be a neg-word, and not carry negative semantic content) started out as a minimizer ('not even one step'), but didn't retain its minimizer meaning; like other neg-words, it is a licenser of negation (as first claimed by Milner 1979) and an NPI; its meaning could plausibly be that of an indefinite, i.e., in any way.

$$
\begin{aligned}
& \text { Jean ne boit pas. } \\
& \text { Jean NE drinks PAS } \\
& \text { 'Jean doesn't drink.' }
\end{aligned}
$$

If nahĩ: is not negative, it is an associate of some higher, covert, morpheme ('NEG'), which is intrinsically negative and as such can be diagnosed by scope tests (NEG is higher than the canonical position of subjects, Sect. 2.3) and NPI licensing. ${ }^{35}$ The associate nahi: can be left-attached (left-attachment entails that nahĩ: is not negative (21), because of scope relations), or right-attached. Under either version of this hypothesis, the 'nahĩ: $\mathrm{V}_{1} \mathrm{~V}_{2}$ ' word order is no longer evidence for verb clustering. In subsections 5.1-5.3, we discuss and eventually rule out this hypothesis.

\subsection{Left-attachment in the embedded clause}

Suppose first that in complex sentences, when NEG is in the matrix, the nahi: that signals its presence need not be in the same clause, but can be in an embedded clause, provided that certain locality conditions, i.e., presumably, restructuring, are met. The idea here would be: the abstract NEG requires nahĩ: in its scope, and nahĩ: has to be predicate adjacent; but it need not be adjacent to the closest predicate.

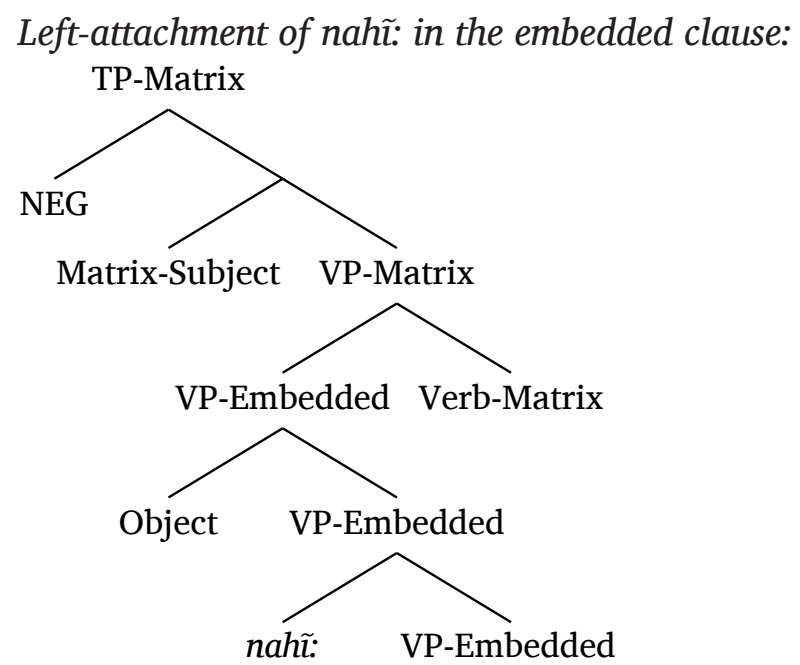

\footnotetext{
35 If the abstract negation hypothesis is correct, then the semantic criteria that we used to determine whether negation can be interpreted in embedded clauses (Sect. 4.2) reveal which complements have enough structure to host this abstract negation.
} 
The placement of kyaa 'what' w.r.t. nahĩ: lends some plausibility to this idea. Wh-words in Hindi-Urdu have a strong tendency to be immediately pre-verbal. This tendency is particularly pronounced in the case of kyaa 'what', with which scrambling leads to deviance:
a. Ram-ne Sita-ko kyaa diyaa
Ram-ERG Sita-DAT what give.PFV
'What did Ram give to Sita?'
b. ??Ram-ne kyaa Sita-ko diyaa
Ram-ERG what Sita-DAT give.PFV
Intended: 'What did Ram give to Sita?'

Let us assume that this is because kyaa 'what' cannot be scrambled. If so, then the following example, where the matrix Aux can be deleted, shows a case where scrambling cannot be used to achieve the exceptional behavior of negation and nahĩ: (if left-attached) is thus in the embedded:

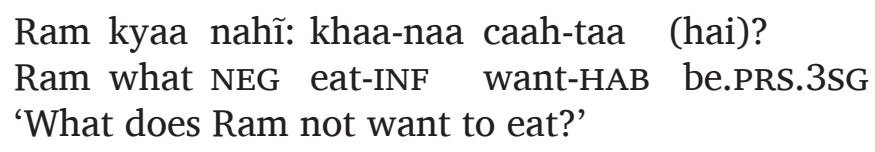

If nahĩ: was attached to the matrix clause, then kyaa would have to scramble over it. Given that scrambling of kyaa leads to deviance, the non-deviance of (91) tells us that there is no scrambling involved: therefore if nahĩ: is left-attached in (91), it is not in the matrix but in the embedded clause. Note that the exceptional behavior of negation doesn't require verb clustering under such assumptions: while NEG has matrix licensing effects, its associate nahĩ: precedes the embedded $\mathrm{V}$ on the surface.

It appears then that if nahĩ: is not negative it can be left-attached in an embedded clause.

\subsection{Left-attachment in the matrix clause}

We expect that we can left-attach non-negative nahĩ: to the matrix VP as well. We would have to scramble material from the infinitival clause to nahĩ: in order to achieve the 'nahĩ: V1 V2' order under the exceptional behavior of negation:

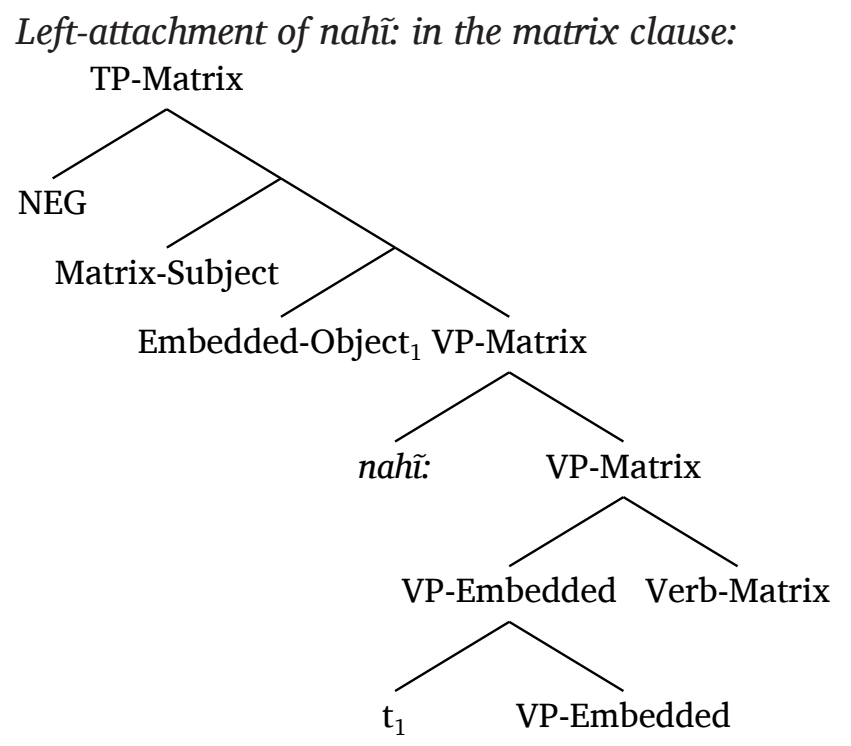

Left-adjoining nahĩ: is potentially problematic as nahĩ: is in general not discontinuous from the verbal complex (in simplex clauses, the strict adjacency between nahĩ: and V in 
the 'nahĩ: V' order would be mysterious). The following is an additional argument against this possibility.

We know that when nahi: is (or appears to be) inside a non-restructuring infinitive matrix NPIs and matrix auxiliary deletion are not licensed ((35)-(36), (38)-(39)). And yet scrambling out of non-restructuring infinitives is possible in Hindi-Urdu:

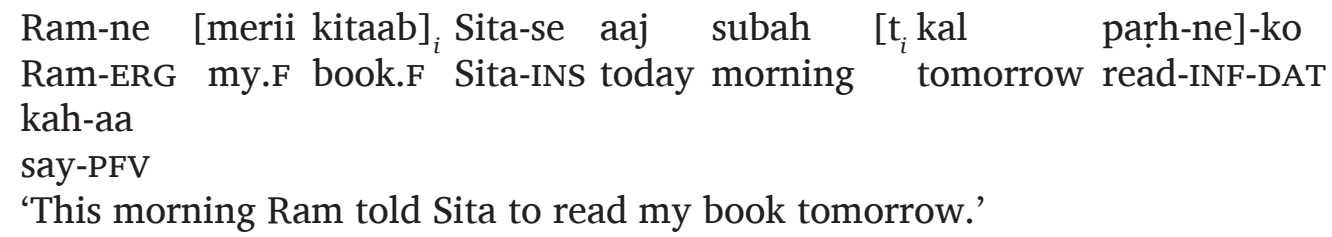

Since scrambling is in fact possible quite generally, we presume that it could, in concert with the left-attached non-negative nahi: hypothesis, derive exceptional behavior of negation out of non-restructuring complements, contrary to fact. It must then be that left-adjunction to matrix VP is unavailable, as it would overgenerate.

The hypothesis that nahĩ: is non-negative and left-attached predicts that two options are possible in complex sentences: left-attachment in the embedded clause and left-attachment in the matrix clause:

\section{Prediction of the left-attached non-negative nahĩ: hypothesis: \\ nahĩ: can be attached in the matrix clause \& nahĩ: can be attached in the embedded clause.}

Left-attachment in the embedded clause might seem to be a viable option (Sect. 5.1), but we have shown that the more likely option, left-attachment in the matrix clause, is ruled out (Sect. 5.2): one of the conjuncts in (94) (the more likely one) is false. Therefore the left-attachment hypothesis is disproved or highly implausible.

\subsection{Right-attachment of 'nahĩ:'?}

Under the non-negative nahĩ: hypothesis, the remaining options are, for complex sentences: attachment of nahĩ: to the right of the embedded VP or to the right of the matrix VP (the reasoning holds whether it is a head or not). If the former option is indeed available, then it is possible to explain matrix licensing effects under the 'nahĩ: $\mathrm{V}_{1} \mathrm{~V}_{2}$ ' word order, i.e., the 'exceptional behavior', without verb clustering: the exceptional behavior obtains if NEG is in the matrix (it has matrix licensing effects), nahĩ: is in the embedded clause and the embedded $\mathrm{V}$ moves to the embedded nahĩ:. This doesn't mean that verb clustering is impossible under such assumptions; it simply means that, if it is real $\left(\mathrm{V}_{\text {embed }}\right.$ and $\mathrm{V}_{\text {matrix }}$ form a cluster that raises to a matrix nahĩ:), it cannot be ascertained.

However an argument against the non-negative nahĩ: hypothesis (in both of its versions, i.e., left or right-attachment) can be made by noting that, when nahĩ: is inside a scrambled infinitive (which we know can be restructuring, cf. (76)), matrix licensing effects are blocked (60): it is unclear why displacing nahĩ: the associate of the abstract negation, by moving the complement of the verb, should lead to deviance.

\section{A comparison with Keine \& Bhatt 2016}

Keine \& Bhatt (2016) present an analysis of the long passive construction in German with which our analysis shares a number of important features. They propose that restructuring infinitival complements undergo obligatory string-vacuous head movement whenever the infinitival verb and the main verb are adjacent. However, this movement is not an 
essential part of the long passive construction. This movement is blocked if the adjacency between the two verbs is disrupted as happens if the embedded VP is moved but the long passive remains an option. Thus far, the analysis of the German long passive and the treatment of the Hindi-Urdu construction is strikingly similar. Both involve string-vacuous head movement and in both cases, non-adjacency between the verbs blocks head movement; we claim that in Hindi-Urdu (but not in German) adjacency can be disrupted by string-vacuous movement of the infinitival complement, hence the apparent optionality of clustering.

There is a significant difference between the two languages. In Keine \& Bhatt 2016, the head movement operation is semantically contentful. The two verbs combine via function composition and a consequence of this in the system is that all quantificational material inside the infinitival clause has to take scope over the matrix clause, a consequence of which is that only de re readings are available for embedded indefinites: ${ }^{36}$

(95) Long passive: de re/*de dicto

Gestern wurden zwei gute Studenten zu finden versucht. yesterday were two good students.NOM to find tried Lit.: 'Yesterday it was tried to find two good students.'

(96) Local passive: de re/de dicto

Gestern wurde zwei gute Studenten zu finden versucht. yesterday was two good students.ACC to find tried Lit.: 'Yesterday it was tried to find two good students.'

Moreover adjuncts inside the infinitival clause are construed with the matrix clause.

(97) Long passive: only matrix construal of adjunct

\#Erst gestern wieder wurde der Traktor mit einem Spezialwerkzeug just yesterday again was the tractor.NOM with a special.tool zu reparieren vergessen.

to repair forgotten

Lit.: 'Just yesterday it was forgotten with a special tool to repair the tractor.'

(98) Local passive: embedded construal of adjunct possible

Erst gestern wieder wurde den Traktor mit einem Spezialwerkzeug

just yesterday again was the tractor.ACC with a special.tool

$\mathrm{zu}$ reparieren vergessen.

to repair forgotten

Lit.: 'Just yesterday it was forgotten to repair the tractor with a special tool.'

These semantic effects are not found in their closest Hindi-Urdu counterparts-HindiUrdu does not have a long passive but it does have restructuring infinitives which can be diagnosed by Long Distance Agreement and verb clustering. We find that both de re and de dicto readings are possible but the de dicto reading with the ' $\neg \gg \mathrm{ANY}_{-}$

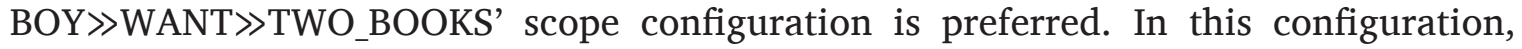
there is no boy with a desire to read two (non-specific) books. If, like in German, two books was forced to take scope over want, this reading would have been unavailable:

\footnotetext{
${ }^{36} \mathrm{By}$ 'de re readings', we mean readings where the quantificational force of the indefinite has wide scope over the intensional verb and the restrictor is transparent, as opposed to de dicto readings, characterized by a narrow scope quantification and an opaque restrictor.
} 
ek-bhii laṛke-ne do kitaabẽ nahĩ paṛhni: caah-1̃:

one-even boy-ERG two books.F NEG read.INF.F want.PFV.F.PL

'Not even a single boy wanted to read two books.'

Both de re and de dicto possible, de dicto preferred

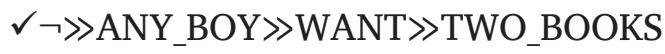

Likewise, embedded construal of adjuncts is possible with LDA and verb clustering (diagnosed by the exceptional behavior of negation):

(100) ek-bhii laṛke-ne churi:-kã:țe-se roții nahĩ: khaa-nii caah-ii one-even boy-ERG knife-fork-INS bread.F NEG eat-INF.F want-PFV.F 'Not even a single boy wanted to eat bread with a knife and fork.'

We do not have a full understanding of why the Hindi-Urdu cases of restructuring and the German cases of long passive differ in the way they do. One possible line of investigation would relate this difference to the fact that even restructuring complements in Hindi-Urdu constitute their own case domain (see Bhatt 2005) as opposed to German where Wurmbrand (2001) has argued based on data from the long passive that the embedded infinitival in restructuring infinitivals is dependent on the matrix predicate for case-licensing.

\section{Conclusion}

Verb cluster formation is a test for restructuring in Hindi-Urdu, along with Long Distance Agreement: it can only occur out of restructuring infinitives. This clustering can be diagnosed by the exceptional behavior of negation, whereby negation seems to be embedded in an infinitive, due to the 'nahĩ: V1 V2' order, and yet is interpreted in the matrix, as indicated directly by its scope w.r.t. the embedding verb (for non-neg-raising predicates), or by its licensing effects in the matrix. Using our two restructuring tests, we've uncovered a threeway distinction among infinitival complements in Hindi-Urdu: vP, AspP and TP. Only the first two can be restructuring environments. LDA only occurs with vP complements. AspP complements, which modal verbs do not select for, are opaque to LDA, but permit clustering.

\section{Appendix: The exceptional behavior is not due to neg-raising}

Many of our examples where negation exhibits an exceptional behavior have the restructuring verb caah 'want' as their matrix verb. Since it is also a neg-raising predicate, it is tempting to derive the exceptional behavior of negation from this aspect of its semantics. The reading that obtains is one where negation seems to be interpreted in the embedded clause, similarly to what we find in the following English example:

(101) Mary doesn't want to help me.

$\checkmark$ WANT $\gg \neg$

In (101), negation surfaces in the matrix, but the sentence is (preferentially) paraphrasable as: 'Mary wants to not help me.' Only certain embedding verbs allow for this scope reversal; want is one of them. We already know that neg-raising is not necessary for the exceptional behavior of negation, since the latter occurs with non-neg-raisers, e.g., shuruu kar 'start' (Sect. 4); here we show that it is not sufficient either.

Suppose that the syntactic approaches to neg-raising, known as 'negative transportation' theories (Fillmore 1963; Lakoff 1969; Ross 1973; Seuren 1974; Prince 1976; Collins \& Postal 2014; 2017 a.o.) are correct: ${ }^{37}$ then we can imagine that despite being realized in the embedded clause in Hindi-Urdu, negation covertly raises in the matrix, but still gets

\footnotetext{
37 We do not endorse any of these approaches: the semantic approach to neg-raising defended by Gajewski (2007) a.o. is both elegant and empirically adequate, and it doesn't rely on the movement of negation, which we claim to be problematic (see Sect. 4.5).
} 
interpreted in the low position, as in English; in a sense then Hindi-Urdu would show us an example where the tail of the negative chain (the interpreted copy) is realized, while the head of the chain is silent. Although it could perhaps capture auxiliary deletion as an effect of the presence of a silent copy of NEG in the matrix, such an account faces an immediate challenge: NPIs need to be licensed at LF, therefore a low interpretation of negation is at odds with the licensing of NPIs in the matrix.

We offer an additional argument against this line of reasoning. Caah 'want' can embed infinitival complements but it can also embed finite subjunctive complements. The choice of complement does not influence the neg-raising property of caah 'want':

(102) nahĩ: in the matrix:

Ram (yeh) nahĩ: caah-taa hai [ki Sita Dilli jaa-e $]$

Ram this NEG want-HAB be.PRS.SG that Sita Delhi go-SBJV.3

'Ram doesn't want that Sita go to Delhi.'

$\checkmark$ WANT $\gg \neg$

(103) nahĩ: in the subjunctive complement:

Ram (yeh) caah-taa hai [ki Sita Dilli naa/nahĩ: jaa-e]

Ram this want-HAB be.PRS.SG that Sita Delhi NEG go-SBJV.3

'Ram wants that Sita not go to Delhi.'

(102) has a neg-raised reading, under which it is a paraphrase of (103). Now, despite the presence of a neg-raising semantics, embedded negation in subjunctive clauses is not enough to license matrix NPIs or matrix auxiliary deletion:

(104) No matrix auxiliary deletion:

*Ram (yeh) caah-taa [ki Sita Dilli naa/nahĩ: jaa-e]

Ram this want-HAB that Sita Delhi NEG go-SBJV.3

Intended: 'Ram wants that Sita not go to Delhi.'

(105) No matrix NPI licensing:

*ek-bhii larkaa (yeh) caah-taa hai [ki Sita Dilli naa/nahĩ: jaa-e]

one-even boy this want-HAB be.PRS.SG that Sita Delhi NEG go-SBJV.3

Intended: 'Not even a single boy wants Sita to go to Delhi.'

The following example is a control showing that, contrary to embedded nahĩ:, matrix nahĩ: has the expected effects:

(106) Matrix negation and auxiliary deletion/NPI licensing:

ek-bhii larka: (yeh) nahĩ: caah-taa (hai) [ki Sita Dilli jaa-e]

one-even boy this NEG want-HAB be.PRS.SG that Sita Delhi go-SBJV.3

'Not even one boy wants that Sita go to Delhi.'

As far as the exceptional behavior of negation is concerned, subjunctive complements behave like finite clauses: neg-raising is not sufficient to derive the cluster of properties we are interested in.

\section{Abbreviations}

The following abbreviations are used in this article:

$1=1^{\text {st }}$ person, $2=2^{\text {nd }}$ person, $3=3^{\text {rd }}$ person, ACC $=$ accusative, AUX $=$ auxiliary, $\mathrm{DAT}=$ dative, $\mathrm{DEF}=$ default, $\mathrm{ERG}=$ ergative, $\mathrm{F}=$ feminine, $\mathrm{FUT}=$ future, $\mathrm{GEN}=$ 
genitive, $\mathrm{HAB}=$ habitual, $\mathrm{HON}=$ honorific, $\mathrm{INF}=$ infinitive, INS $=$ instrumental, IPFV $=$ imperfective, $\mathrm{M}=$ masculine, $\mathrm{NEG}=$ negation, $\mathrm{NOM}=$ nominative, $\mathrm{OBL}=$ oblique, $\mathrm{PFV}=$ perfective, $\mathrm{PL}=$ plural, $\mathrm{PROG}=$ progressive, $\mathrm{PRS}=$ present, $\mathrm{PST}=$ past, $\mathrm{SBJV}=$ subjunctive, $\mathrm{SG}=$ singular

\section{Acknowledgements}

This article has benefitted from feedback from Stefan Keine, Veneeta Dayal and Kinjal Joshi, and from audiences at UMass Amherst, FASAL 4 at Rutgers University and LISSIM 8. We are especially grateful to Mark Baker for a comment during the question session of our FASAL talk that encouraged us to explore the verb cluster formation idea. Our thanks also go to our Glossa anonymous reviewers and editors.

\section{Competing Interests}

The authors have no competing interests to declare.

\section{References}

Aissen, Judith L. \& David M. Perlmutter. 1983. Clause reduction in Spanish. In D. M. Perlmutter (ed.), Studies in relational grammar 1. 360-404. University of Chicago Press. DOI: https://doi.org/10.3765/bls.v2i0.2283

Alonso-Ovalle, Luis \& Elena Guerzoni. 2004. Double negatives, negative concord and metalinguistic negation. In Anne Pycha, Mary Andronis, Erin Debenport \& Keiko Yoshimura (eds.), Chicago Linguistic Society (CLS) 38, 15-31. Chicago, IL: Chicago Linguistic Society Publications.

Baker, Mark C. 1985. The mirror principle and morphosyntactic explanation. Linguistic Inquiry 16(3). 373-416.

Baker, Mark C. 1988. Incorporation: A theory of grammatical function changing. University of Chicago Press.

Bartsch, Renate. 1973. "Negative transportation" gibt es nicht. Linguistische Berichte 27(7).

Béjar, Susana \& Milan Rezac. 2009. Cyclic Agree. Linguistic Inquiry 40(1). 35-73. DOI: https://doi.org/10.1162/ling.2009.40.1.35

Bhatia, Tej K. 1978. A syntactic and semantic description of negation in South Asian languages. Urbana-Champaign, Illinois: University of Illinois-Urbana dissertation.

Bhatt, Rajesh. 2005. Long distance agreement in Hindi-Urdu. Natural Language and Linguistic Theory 23. 757-807. DOI: https://doi.org/10.1007/s11049-004-4136-0

Bhatt, Rajesh \& Stefan Keine. 2017. Tense and the realization of the feminine plural in Hindi-Urdu. In G. Sengupta, S. Sircar, M. G. Raman \& R. Balusu (eds.), Perspectives on the architecture and acquisition of syntax, 49-76. Springer. DOI: https://doi.org/10.1007/ 978-981-10-4295-9_3

Butt, Miriam. 1995. The structure of complex predicates in Urdu. Stanford, CA: Stanford University dissertation.

Cardinaletti, Anna \& Ur Shlonsky. 2004. Clitic positions and restructuring in Italian. Linguistic Inquiry 35(4). 519-557. DOI: https://doi.org/10.1162/0024389042350523

Chierchia, Gennaro. 2004. Scalar implicatures, polarity phenomena, and the syntax/pragmatics interface. In A. Belletti (ed.), Structures and beyond, 39-103. Oxford: Oxford University Press.

Collins, Chris \& Paul M. Postal. 2014. Classical NEG raising. An essay on the syntax of negation (Linguistic Inquiry Monographs). Cambridge, MA: MIT Press. DOI: https:// doi.org/10.7551/mitpress/9704.003.0031 
Collins, Chris \& Paul M. Postal. 2017. Interclausal NEG raising and the scope of negation. Glossa: A Journal of General Linguistics 2(1). 1-29. DOI: https://doi.org/10.5334/ gjgl.79

Davison, Alice. 2001. Long-distance anaphors in Hindi/Urdu: Syntactic and semantic issues. In P. Cole, G. Hermon \& C-T. J. Huang (eds.), Long distance reflexives, 47-82. San Diego: Academic Press. DOI: https://doi.org/10.1163/9781849508742_003

Dayal, Veneeta Srivastav. 1996. Locality in wh quantification (Studies in Linguistics and Philosophy). Springer. DOI: https://doi.org/10.1007/978-94-011-4808-5

Fillmore, Charles. 1963. The position of embedding transformations in grammar. Word 19. 208-231. DOI: https://doi.org/10.1080/00437956.1963.11659796

Gajewski, Jon. 2007. Neg-raising and polarity. Linguistics and Philosophy 30(3). 289-328. DOI: https://doi.org/10.1007/s10988-007-9020-z

Gribanova, Vera \& Line Mikkelsen. 2018. On the interaction of head movement and ellipsis in Danish. In Jason Merchant, Line Mikkelsen, Deniz Rudin \& Kelsey Sasaki (eds.), A reasonable way to proceed: Essays in honor of Jim McCloskey, 105-123. UC Santa Cruz.

Haider, Hubert. 1993. Deutsche syntax - generativ. Tübingen: Narr.

Haider, Hubert. 2003. V-clustering and clause union: Causes and effects. In Pieter Seuren \& Gerard Kempen (eds.), Verb constructions in German and Dutch, 91-126. Amsterdam: John Benjamins Pub Co. DOI: https://doi.org/10.1075/cilt.242.04hai

Haider, Hubert. 2010. The syntax of German. Cambridge: Cambridge University Press. DOI: https://doi.org/10.1017/CBO9780511845314

Harizanov, Boris \& Vera Gribanova. 2019. Whither head movement? Natural Language and Linguistic Theory 37(2). 461-522. DOI: https://doi.org/10.1007/s11049-0189420-5

Homer, Vincent. 2019. Negative polarity. In Lisa Matthewson, Cécile Meier, Hotze Rullman \& Thomas Ede Zimmermann (eds.), Blackwell companion to semantics, Wiley (forthcoming).

Homer, Vincent \& Rajesh Bhatt. 2019. Licensing of PPI indefinites: Movement or pseudoscope? Natural Language Semantics 27(4). 279-321. DOI: https://doi.org/10.1007/ s11050-019-09155-6

Homer, Vincent \& Tristan Thommen. 2013. Remarks on a language with no overt negation. Paper presented at the $14^{\text {th }}$ Szklarska Poreba Workshop.

Hook, Peter Edwin. 1974. The compound verb in Hindi (Michigan Series in South and Southeast Asian Languages and Linguistics 1). Ann Arbor, Michigan: University of Michigan, Center for South and Southeast Asian Studies.

Horn, Laurence R. 1989. A natural history of negation. University of Chicago Press.

Houser, Michael J., Line Mikkelsen \& Maziar Toosarvandani. 2011. A defective auxiliary in Danish. Journal of Germanic Linguistics 23(3). 245-298. DOI: https://doi.org/10.1017/ S1470542711000043

Iatridou, Sabine \& Ivy Sichel. 2015. Some thoughts about NegDP (de)composition. Jerusalem Workshop on Syntax-Semantics.

Joshi, Kinjal. 2019. Agreement puzzles in Surati Gujarati. Unpublished manuscript, University of Oslo.

Keine, Stefan. 2016. Probes and their horizons. Amherst, MA: UMass Amherst dissertation. Keine, Stefan \& Rajesh Bhatt. 2016. Interpreting verb clusters. Natural Language and Linguistic Theory 34(4). 1445-1492. DOI: https://doi.org/10.1007/s11049-015-9326-4

Koopman, Hilda. 1984. The syntax of verbs: From verb-movement rules in the Kru languages to universal grammar. Dordrecht: Foris Publications. 
Kumar, Rajesh. 2006. The syntax of negation and the licensing of negative polarity items in Hindi (Outstanding Dissertations in Linguistics). London: Routledge. DOI: https://doi. org/10.4324/9780203959763

Ladusaw, William A. 1992. Expressing negation. In Chris Barker \& David Dowty (eds.), Semantics and Linguistic Theory (SALT) 2, 237-259. Columbus: Ohio State University. DOI: https://doi.org/10.3765/salt.v2i0.3030

Lahiri, Utpal. 1998. Focus and negative polarity in Hindi. Natural Language Semantics 6(1). 57-123. DOI: https://doi.org/10.1023/A:1008211808250

Laka, Itziar. 1990. Negation in syntax: On the nature of functional categories and projections. Cambridge, MA: MIT dissertation.

Lakoff, Robin. 1969. A syntactic argument for negative transportation. In Chicago Linguistic Society (CLS) 5, 140-147.

Linebarger, Marcia C. 1980. The grammar of negative polarity. Cambridge, MA: MIT dissertation.

Mahajan, Anoop Kumar. 1989. Agreement and agreement phrases. In Itziar Laka \& Anoop Kumar Mahajan (eds.), Functional heads and clause structure (MIT Working Papers in Linguistics 10), 217-252. Cambridge, MA: MITWPL.

Mahajan, Anoop Kumar. 1990. LF conditions on negative polarity licensing. Lingua 80(4). 333-348. DOI: https://doi.org/10.1016/0024-3841(90)90037-L

Milner, Jean-Claude. 1979. Le système de la négation en français et l'opacité du sujet. Langue française 44. 80-105. DOI: https://doi.org/10.3406/lfr.1979.6171

Nevins, Andrew \& Pranav Anand. 2003. Some AGREEment matters. In Gina Garding \& Mimu Tsujimura (eds.), West Coast Conference on Formal Linguistics (WCCFL) 22. 370383. Somerville, MA: Cascadilla Press.

Pancheva, Roumyana \& Arnim von Stechow. 2004. On the present perfect puzzle. In Keir Moulton \& Matthew Wolf (eds.), North East Linguistic Society (NELS) 34, 469-484. GLSA, University of Massachusetts.

Penka, Doris. 2010. Negative indefinites. Oxford University Press. DOI: https://doi.org/ 10.1093/acprof:oso/9780199567263.001.0001

Prince, Ellen F. 1976. The syntax and semantics of neg-raising, with evidence from French. Language 52(2). 404-426. DOI: https://doi.org/10.2307/412568

Rizzi, Luigi. 1978. A restructuring rule in Italian syntax. In S. J. Keyser (ed.), Recent transformational studies in European languages, vol. 3 (Linguistic Inquiry Monographs), 113-158. Cambridge, MA: MIT Press.

Ross, John Robert. 1973. Slifting. In M. P. Schutzenburger, M. Gross \& M. Halle (eds.), The formal analysis of natural languages: Proceedings of the first international conference. The Hague, The Netherlands: Mouton. DOI: https://doi.org/10.1515/9783110885248009

Rowlett, Paul. 1998. A non-overt negative operator in French. Probus 10. 185-206. DOI: https://doi.org/10.1515/prbs.1998.10.2.185

Seuren, Pieter. 1974. Negative's travels. In Pieter Seuren (ed.), Semantic syntax, 96-122. Oxford, England: Oxford University Press.

Sternefeld, Wolfgang. 2001. Semantic vs. syntactic reconstruction. In Christian Rohrer, Antje Roßdeutscher \& Hans Kamp (eds.), Linguistic form and its computation, 145-182. Stanford, CA: CSLI Publications.

Travis, Lisa. 1984. Parameters and effects of word order variation. Cambridge, MA: MIT dissertation.

Wurmbrand, Susi. 2001. Infinitives: Restructuring and clause structure. Berlin/New York: Mouton de Gruyter. DOI: https://doi.org/10.1515/9783110908329 
Wurmbrand, Susi. 2014. Restructuring across the world. In Ludmila Veselovská \& Markéta Janebová (eds.), Complex visibles out there. Proceedings of the Olomouc linguistics colloquium 2014: Language use and linguistic structure, 275-294. Olomouc: Palacký University.

Wurmbrand, Susi. 2015. Restructuring cross-linguistically. In Thuy Bui \& Deniz Özyıldız (eds.), North East Linguistic Society (NELS) 45, 227-240. University of Massachusetts Amherst: GLSA.

Wurmbrand, Susi. 2017. Verb clusters, verb raising, and restructuring. In M. Everaert \& H. C. Riemsdijk (eds.), The Wiley Blackwell companion to syntax, Second Edition. Wiley Online Library. DOI: https://doi.org/10.1002/9781118358733.wbsyncom103

Zeijlstra, Hedde. 2008. On the syntactic flexibility of formal features. In Theresa Biberauer (ed.), The limits of syntactic variation, 143-173. Amsterdam: John Benjamins. DOI: https://doi.org/10.1075/la.132.06zei

\footnotetext{
How to cite this article: Homer, Vincent and Rajesh Bhatt. 2020. Restructuring and the scope of negation in Hindi-Urdu. Glossa: a journal of general linguistics 5(1): 12.1-36. DOI: https://doi.org/10.5334/gjgl.927

Submitted: 24 February 2019 Accepted: 09 October 2019 Published: 21 February 2020

Copyright: $\odot 2020$ The Author(s). This is an open-access article distributed under the terms of the Creative Commons Attribution 4.0 International License (CC-BY 4.0), which permits unrestricted use, distribution, and reproduction in any medium, provided the original author and source are credited. See http://creativecommons.org/licenses/by/4.0/.
} 